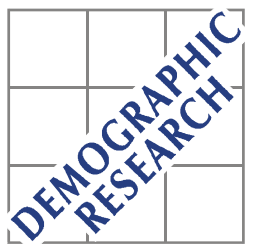

Demographic Research a free, expedited, online journal of peer-reviewed research and commentary in the population sciences published by the Max Planck Institute for Demographic Research Konrad-Zuse Str. 1, D-18057 Rostock · GERMANY www.demographic-research.org

DEMOGRAPHIC RESEARCH

VOLUME 11, ARTICLE 8, PAGES 195-234

PUBLISHED 23 September 2004

www.demographic-research.org/Volumes/Vol1 1/8/

DOI: 10.4054/DemRes.2004.11.8

Research Article

\title{
Australia's uncertain demographic future
}

\section{Tom Wilson}

Martin Bell

(C) 2004 Max-Planck-Gesellschaft. 


\section{Table of Contents}

1 Introduction 196

2 Methods, data and assumptions 197

$2.1 \quad$ Jump-off populations 199

2.2 Fertility 200

2.3 Mortality 203

$\begin{array}{lll}2.4 & \text { International migration } & 207\end{array}$

3 Results 221

3.1 Total populations 221

3.2 Components of population change 222

$\begin{array}{lll}3.3 & \text { Age-sex structures } & 225\end{array}$

4 Conclusions 229

5 Acknowledgments 230

$\begin{array}{ll}\text { Notes } & 231\end{array}$

References 232 
Research Article

\title{
Australia's uncertain demographic future
}

\author{
Tom Wilson ${ }^{1}$ \\ Martin Bell ${ }^{2}$
}

\begin{abstract}
The techniques of probabilistic population forecasting are increasingly being recognised as a profitable means of overcoming many of the limitations of conventional deterministic variant population forecasts. This paper applies these techniques to present the first comprehensive set of probabilistic population forecasts for Australia. We stress the disadvantages of directly inputting net migration into the cohort component model in probabilistic forecasting, and propose a gross migration flows model which distinguishes between permanent and non-permanent immigration and emigration. Our forecasts suggest that there is a two thirds probability of Australia's population being between 23.0 and 25.8 million by 2026 and between 24.4 and 31.8 million by 2051. Comparisons with the latest official population projections of the Australian Bureau of Statistics are made.
\end{abstract}

1 Queensland Centre for Population Research, School of Geography, Planning and Architecture, The University of Queensland, St Lucia, Brisbane, Qld 4072, Australia. Phone: +62 (0)7 33656704.

Fax: +62 (0)7 3365 6899. Email: tom.wilson@uq.edu.au

2 Queensland Centre for Population Research, School of Geography, Planning and Architecture, The University of Queensland, St Lucia, Brisbane, Qld 4072, Australia. Phone: +62 (0)7 33657087.

Fax: +62 (0)7 3365 6899. Email: martin.bell@uq.edu.au 


\section{Introduction}

Despite the devotion by demographers of much time and effort to population forecasting, the track record in these efforts - except for very short-term forecasts - is mixed. The changes in fertility, mortality and migration over time are not understood sufficiently well for quantitative models to be built in order to provide accurate forecasts of the age-specific rates which need to be input into cohort-component forecasting models. Many population projections have been rather wide of the mark in the medium and long term, particularly in the components of change (births, deaths, and migration) and age disaggregated projected populations (see, for example, Keilman 2001). In fact the one statement that can be made with a very high degree of certainty about a deterministic population forecast is that it will turn out to be wrong (even if only by a small amount).

The traditional way of handling the uncertainty of population forecasts is to produce variants, typically high, low and medium population variants, themselves constructed from combinations of high, low and medium future paths of fertility, mortality and migration. It is increasingly recognised that this approach contains a number of problems, such as the lack of probabilities attached to the variants (Lutz and Scherbov 1998), the smooth trajectories of demographic variables which implicitly assign zero probability to sudden changes, annual fluctuations and cyclical behaviour (Lee 1999), and the fact that the variants are probabilistically inconsistent both between variables and over time (de Beer and Alders 1999). Over the last 15 years or so demographers have overcome these problems by preparing probabilistic population forecasts. In these forecasts a range of future population figures are presented for each year of the forecast horizon along with a probability of the population falling within that range. So far probabilistic population forecasts have been prepared for a number of countries, including Austria (Lutz and Scherbov 1998), Finland (Alho 2002), the Netherlands (de Beer and Alders 1999), Norway (Keilman et al. 2001), Sweden (Cohen 1986), the United States (Lee and Tuljapurkar 1994) and for world regions (Lutz et al. 2001, Lutz et al. 2003a). Probabilistic population forecasts have, in fact, also been produced for Australia. The US National Research Council (2000) used past United Nations projection errors to calculate $95 \%$ confidence intervals for total population that can be applied to deterministic forecasts. More recently, Booth (2004) prepared probabilistic forecasts for Australia, but unfortunately included an assumption of no migration. The need remains, therefore, for a full set of probabilistic population forecasts for Australia.

We believe this paper makes two main contributions. First, we present the first comprehensive set of probabilistic population forecasts for Australia. A particular feature of our forecasts is an age breakdown by single years of age 0-119 with a final 
open-ended age group of $120+$ to deal with the coming expansion of the centenarian population. Second, and more importantly, our model disaggregates international migration into four streams - permanent and non-permanent immigration and emigration - in order to reflect the quite different levels, trends and age-sex profiles of these migration flows. A simple, but effective, method which mimics the strong correlation between non-permanent immigration and emigration is described. This fourstream disaggregation contrasts with the more common approach of modelling immigration and emigration or just net migration.

Following this introduction the paper describes the models, data and assumptions prepared in order to produce the forecasts reported here, dealing in turn with the jumpoff populations, fertility, mortality and international migration. Section 3 then presents the forecast outputs to illustrate the uncertainties in Australia's demographic future, focusing on the total population, the demographic components of change and age structure. Comparisons are made with the latest population projections prepared by the Australian Bureau of Statistics (ABS).

\section{Methods, data and assumptions}

As with most probabilistic population forecasts the standard cohort component model is taken as the starting point. The probabilistic element is incorporated by running the model several thousand times with randomly varying age-specific rates and flows. The resulting forecast population figures are then sorted year by year to give an estimated forecast distribution of future population. The literature suggests three principal methods for producing these distributions of fertility, mortality and migration: (i) model-based approaches, (ii) expert judgement and arguments, and (iii) an analysis based on past forecast errors. For descriptions of the approaches see Keilman et al. (2001) and de Beer and Alders (1999). In practice, most producers of probabilistic population forecasts no longer use any one approach exclusively, instead drawing strength from two or three of them. In our forecasts we relied on time series models adjusted by judgements and arguments, together with some input from analyses of past ABS forecast errors.

Our approach to forecasting may be summarised in six steps.

Step 1. Seven summary indicators of the demographic components of change were chosen: the TFR, male and female life expectancy at birth, permanent immigration, permanent emigration, long-term immigration and long-term emigration. Long-term migration is defined as non-permanent migration involving a minimum residence period of one year. The reasons for selecting these four migration streams are given in section 2.4. 
Step 2. Time series models of all the summary indicators were estimated. Some were adjusted on the basis of judgement and past forecast errors. Details are given in sections 2.2 to 2.4 .

Step 3. The medians of the predictive distributions for the seven summary indicators were formulated, ceiling and floor limits to the predictive distributions set in some cases, and other parameters chosen. Details of these assumptions are also covered in sections 2.2 to 2.4 .

Step 4. For each of the indicators 5,000 random sample paths covering the forecast horizon 2002-51 were generated. If during any simulation a summary indicator exceeded specified ceiling and floor limits for any year that simulation for the whole forecast horizon was rejected and another sample path was generated. This continued until 5,000 sample paths which fell within the limits created for each summary indicator. An example of the sort of random sample paths generated by this process is given in Figure 1, which shows two paths for permanent immigration.

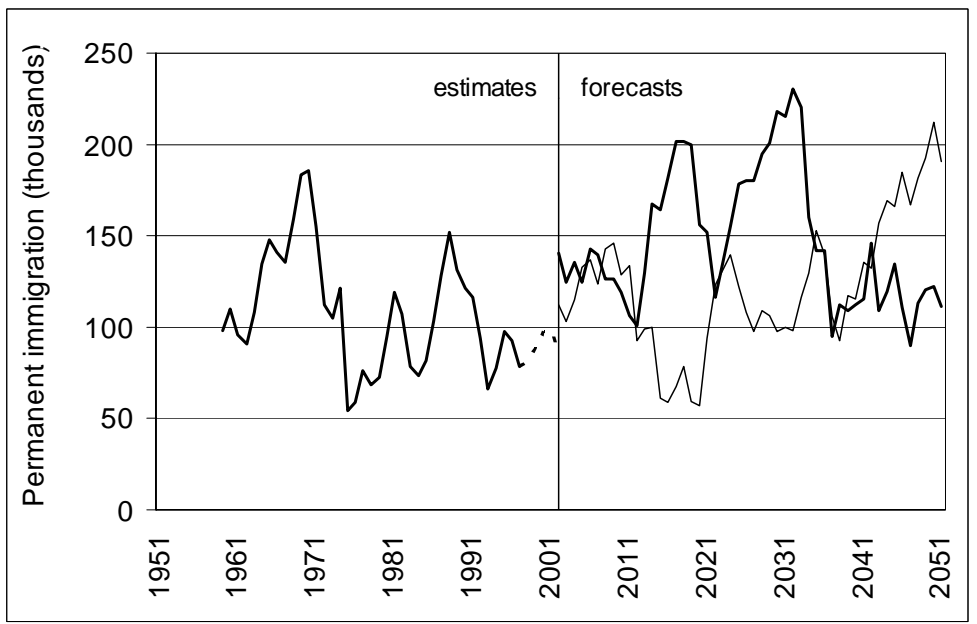

Figure 1: $\quad$ Estimated permanent immigration and two of the 5,000 sample paths

Source of estimates: Australian Bureau of Statistics

Note: random jump-off points were used to deal with the uncertainty over 1997-2002 data, shown as the dashed line.

Step 5. Using a cohort component model, 5,000 simulations of Australia's population over the period 2002-51 were computed. The seven sets of summary indicators were combined piecewise in order of generation (the first of each of the 
5,000 sample paths for each summary indicator in the first run, the second of the sample paths in the second run, and so on). Age-specific rates (for fertility, mortality and emigration) and age-specific proportions (for immigration) were generated during program execution by applying fixed age schedules to the summary indicators. For fertility and both types of immigration this process was very simple: age-specific fertility rates scaled to sum to 1.0 were multiplied by the TFR, and immigration proportions which summed to 1.0 across all age-sex groups were applied to the total immigration figures. For mortality an iterative procedure was used to link the value of $\mathrm{e}_{0}$ to a corresponding set of age-specific death rates. Permanent and long-term emigration forecasts were calculated by scaling the base year emigration rates so that when multiplied by the populations at risk in each age-sex group the resulting emigration numbers summed to the forecast total emigration figure.

Step 6. The results of the probabilistic forecasts were output in 'raw' format, with the populations, births, deaths and migration components from each simulation written to file as they were generated. A separate program was used to sort and summarise selected features of these data. The sorting is needed to calculate selected forecast intervals. For example, a 95\% predictive interval for total population for a specified year is found by calculating total populations for each year from the raw database, sorting them into size order, and selecting the values at $2.5 \%$ and $97.5 \%$ of the way through the 5,000 simulations (i.e. the 125th and 4,876th values). This approach enables us to return to the raw the data and extract summary information very quickly for any selected output variable.

We now turn to the models, data and assumptions used to generate the various model inputs, starting with the jump-off populations, and then describing in turn how the predictive distributions for fertility, mortality and international migration were created.

\subsection{Jump-off populations}

The ABS makes available mid-year population estimates by sex and single years of age 0-99 and 100+. For these forecasts we extended the mid-2002 jump-off populations by single years of age to the highest attained age using the extinct generations and constrained survivor ratio methods described by Thatcher et al. (2002). It was found that the official population estimates in the 90s were inflated somewhat so our own figures were used for ages 90 and above, and the official figures for ages 89 and below. To allow for a rise in the highest attained age in the future the forecasting model was programmed to deal with single years of age up to 119 with $120+$ as the final age group. 


\subsection{Fertility}

The TFR was found to be well represented by an ARIMA(1,1,0) process:

$\operatorname{TFR}(T)=\operatorname{TFR}(T-1)+\phi_{T F R}[T F R(T-1)-T F R(T-2)]+\varepsilon_{T F R}(T)+c_{T F R}(T)$

where T denotes a one year forecast interval, $\phi_{T F R}$ is the autoregressive coefficient, $\varepsilon_{T F R}$ are random errors sampled from a normal distribution with a mean of zero, and

$c_{T F R}$ is the constant. The $\phi_{T F R}$ and $\varepsilon_{T F R}$ values are listed in Table 1 and the predictive TFR distribution is shown in Figure 2.

The constant terms consist of small adjustments to gradually shift the median of the predictive distribution from its base year value of 1.736 to our long-run assumption of 1.70. This assumption is based on the belief that the pronatalist policy which was introduced by the Australian Government on 1st July 2004 will probably prevent much further decline in fertility. This policy entitles mothers to claim a $\$ 3000$ maternity payment for each child born, a figure which will rise to $\$ 5000$ by 2008 (Atkins, 2004). A similar, but means-tested, policy has been adopted by the Labor opposition (Australian Labor Party, 2004).

Whilst the initial fit of the ARIMA model was to TFR data over the period from 1921 (the earliest available) we decided to use the error distribution from the model fitted to just 1976-2002, the period of below-replacement fertility in Australia. Using the error distribution from the whole 1921-2002 period not only implies that the social and economic context of childbearing of earlier decades is still relevant today but also gives a $95 \%$ confidence interval for mid-century that extends from -0.4 to 3.8. Clearly, negative TFR values are nonsense and can be prevented by rejecting sample paths with negative values, but the upper limit of 3.8 was also judged too extreme. In contemporary Australian society there is high female participation in higher education and the labour force, much higher wages for women in real terms (and therefore higher opportunity costs of childrearing), considerable control over fertility through modern contraception methods and a changed societal attitude in which childlessness is quite acceptable (McDonald 2003). It seems most unlikely, therefore, that the fertility levels of the 1950s and 60s will return. Even those industrialised countries which have seen rises in fertility in recent times (such as Denmark) or varying trends (such as Sweden) have not, over the last three decades, experienced fertility at anything like that of the Australian baby boom. 
Table 1: $\quad$ Parameter values (standard errors in parentheses)

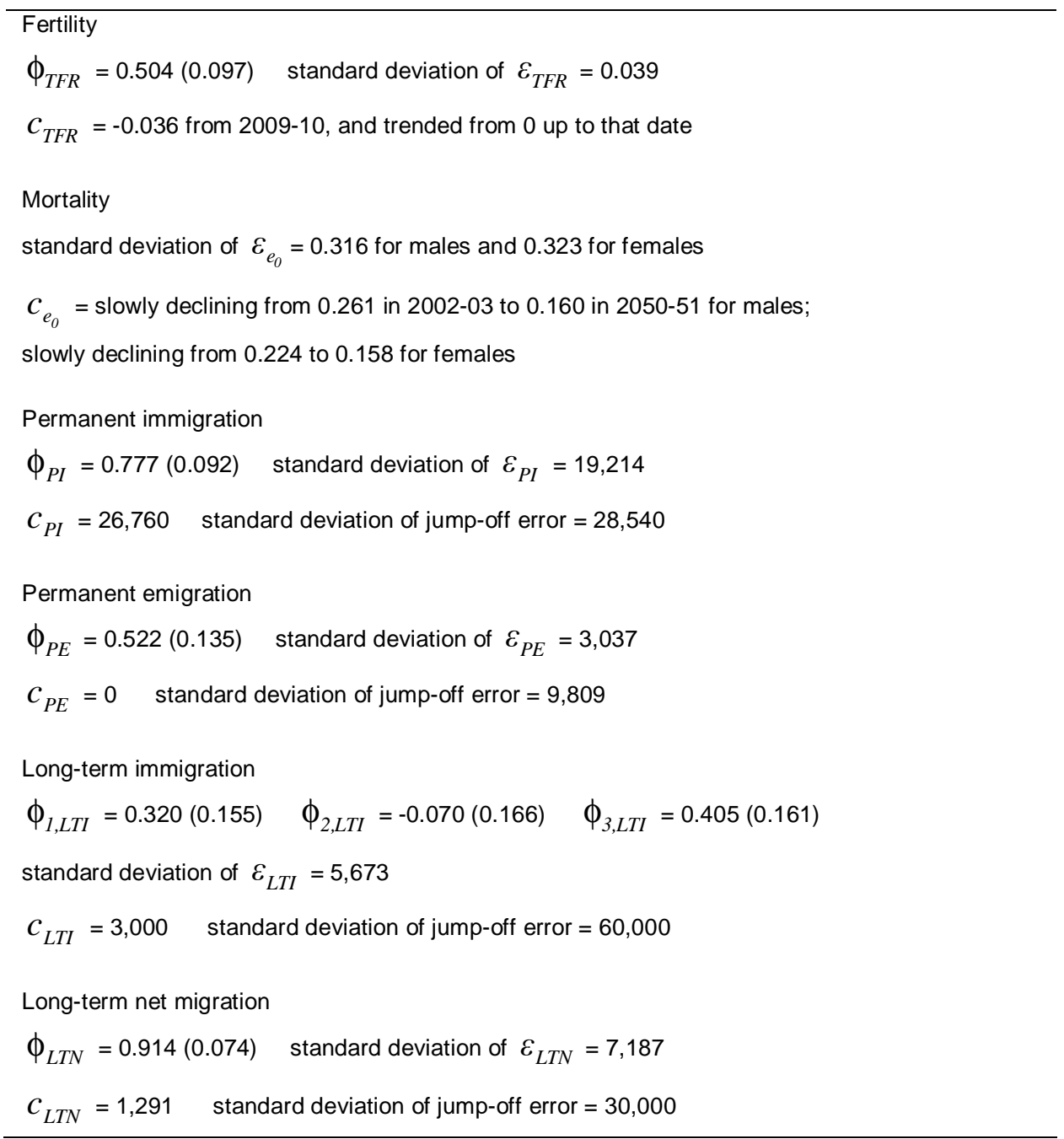

Note: standard errors are not reported for constant values as all such fitted values were adjusted in some way (as described in sections 2.2 to 2.4 ) 


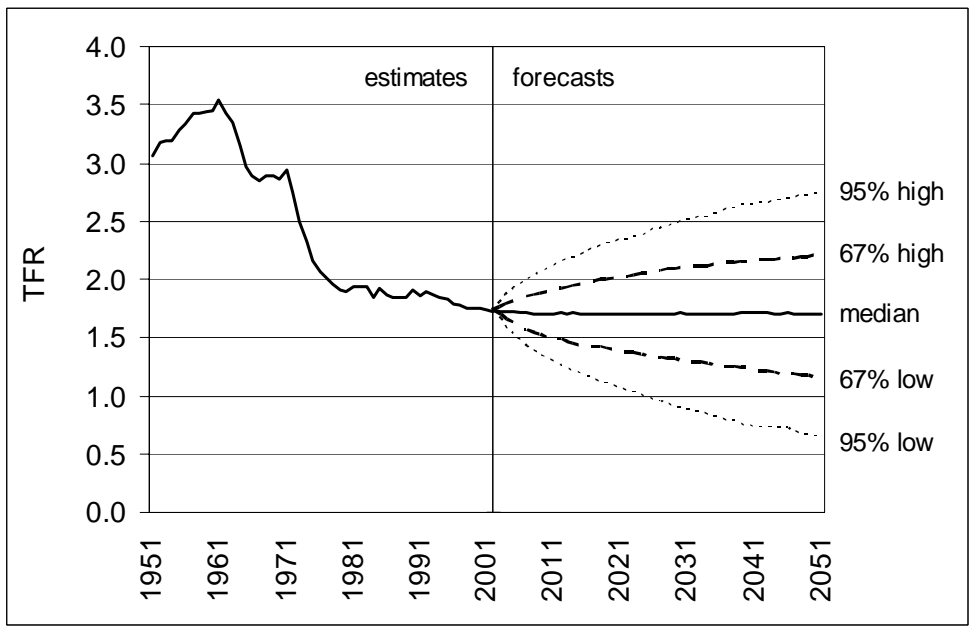

Figure 2: $\quad$ Estimated total fertility rates and prediction interval bounds

Source of estimates: Australian Bureau of Statistics

An analysis of past ABS TFR forecast errors supports our view of the original predictive distribution being too wide. Figure 3 shows the errors for all variants of ABS projections. The standard deviations of the ABS errors are 0.19 after 5 years, 0.29 after 10 years and 0.28 after 15 years, or if the 1970 forecast is excluded, $0.13,0.18$ and 0.18 respectively. In our original predictive distribution the standard deviation of TFR errors was 0.32 after 5 years, 0.44 after 10 and 0.54 after 15 years. Even in our modified predictive distribution the standard deviation after 5 years is $0.14,0.23$ after 10 and 0.29 after 15 years, which is still erring on the side of caution in relation to past errors.

The only additional constraints placed on the TFR forecasts were a floor limit of zero and a ceiling limit of 3.40. Even with the use of the smaller error distribution a handful (about 10) sample paths still contained negative values. The ceiling limit was introduced at the same distance from the long-run assumption as the floor as a simple way of preventing the median and mean of the distribution of sample paths rising upwards away from the long-run assumption. Again, only about 10 sample paths exceeded this limit, making negligible difference to the location of the predictive intervals. 


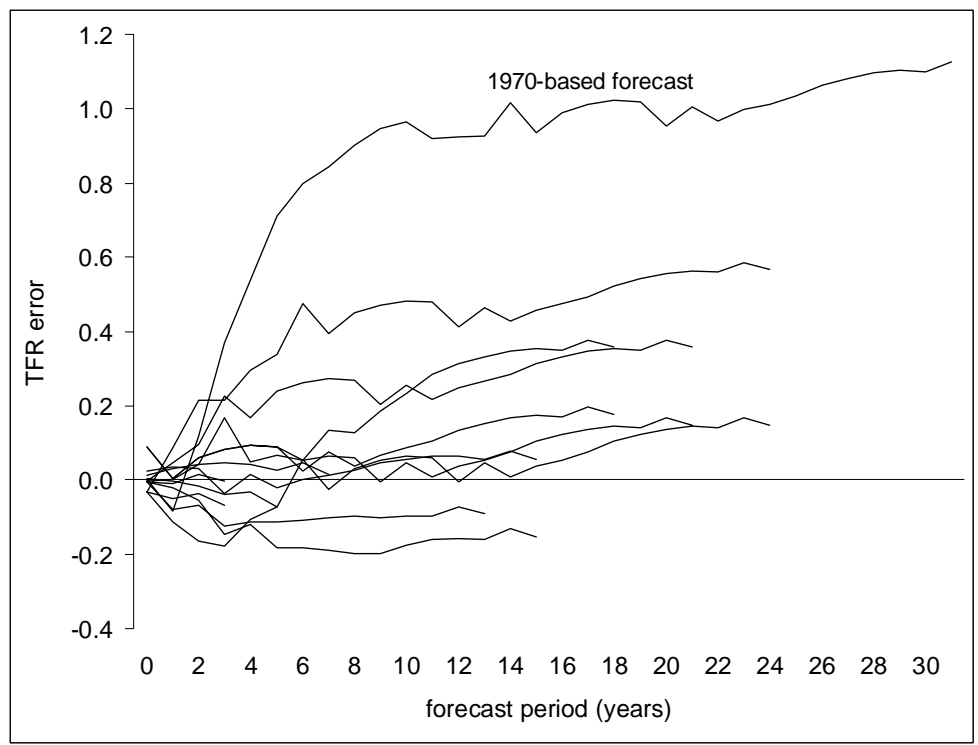

Figure 3: $\quad$ Past ABS TFR forecast errors

Source: $\quad$ calculated from Australian Bureau of Statistics TFR estimates and population projections for jump-off years 1970, 1976, 1978, 1981, 1984, 1987, 1989, 1993, 1995, 1997 and 1999.

\subsection{Mortality}

To model mortality we calculated annual $\mathrm{e}_{0}$ figures from deaths and populations by sex and single years of age from 1971 to 2002, 1971 being the first year for which population estimates based on the usually resident definition are available. Whilst 19712002 would normally be viewed as a rather short time series for forecasting purposes, there are good reasons for not going back much further than 1971. Although the ABS has estimated $\mathrm{e}_{0}$ back to the late nineteenth century these data are averages over three and ten year periods and therefore do not capture the year to year variability needed for modelling. There are a number of other data problems up to the 1960s (see note 1). More importantly, the discontinuity in Australian mortality trends in the late 1960s / early 1970s and fairly steady change since then (AIHW 2000) suggests that the period since this discontinuity is the most sensible to use for forecasting. We note that other researchers have also come to this conclusion. For example, in preparing modified Lee- 


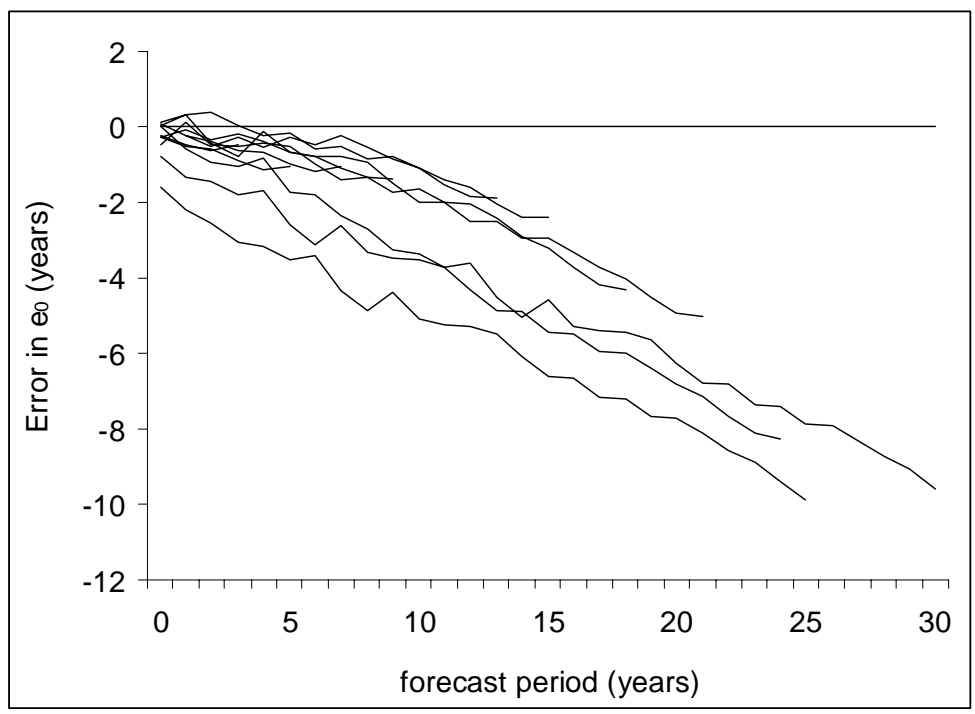

Figure 4: $\quad$ Past ABS forecast errors for male $e_{0}$

Source: $\quad$ calculated from Australian Bureau of Statistics death counts and population estimates, and population projections for jump-off years 1970, 1976, 1978, 1981, 1984, 1987, 1989, 1993, 1995, 1997 and 1999.

Carter mortality forecasts for Australia Booth et al. (2002) found that the optimal fitting period for their model was from 1968 onwards.

In applying the Box-Jenkins model identification procedure it was found for female $e_{0}$ that both a differenced moving average model, ARIMA $(0,1,1)$, and a differenced autoregressive model, $\operatorname{ARIMA}(1,1,0)$, gave almost equally good fits.

For male $\mathrm{e}_{0}$ an $\operatorname{ARIMA}(0,1,1)$ proved unsatisfactory as it had a moving average coefficient of almost 1.0, though an $\operatorname{ARIMA}(1,1,0)$ fitted well. However, forecasts with the differenced autoregressive models gave $95 \%$ predictive intervals which after 10 years were 2.5 years for males and 2.6 years for females; after 50 years these had expanded to only 5.4 years for males and 5.5 years for females. We felt that these intervals were uncomfortably narrow, particularly when compared to past ABS errors in forecasting $\mathrm{e}_{0}$. Figure 4 shows errors in forecasting male $\mathrm{e}_{0}$ from several $\mathrm{ABS}$ projections.

We therefore decided to fit a simple random walk with drift model for male and female life expectancy at birth because of the wider predictive intervals it generated. By 
2051 we obtained $95 \%$ ranges of 8.7 years for males and 8.8 years for females. The model may be described as:

$e_{0}(s, T)=e_{0}(s, T-1)+\varepsilon_{e_{0}}(s, T)+c_{e_{0}}(s, T)$

where s denotes sex, $\varepsilon_{e_{0}}$ is randomly drawn from a normal distribution of error values with a mean of zero and $c_{e_{0}}$ is a constant. Parameter values are given in Table 1. Given that the factors which affect mortality are likely to influence both male and female life expectancy at birth similarly, it is not surprising to find that the $\varepsilon_{e_{0}}$ values are highly correlated $(r=0.914)$. In forecasting the sample paths, therefore, correlated random numbers for male and female $\mathrm{e}_{0}$ errors were produced. These were obtained via a Cholesky decomposition of the variance- covariance matrix (Press et al. 2001: 89-91). No ceiling and floor constraints were applied to the $\mathrm{e}_{0}$ sample paths.

Rather than use the constant values obtained from the model fitting procedure we decided to adjust them so that the medians of the predictive distributions matched those of separate $\mathrm{e}_{0}$ forecasts based on extrapolated age-specific death rates. We took this approach because the literature on the future of mortality, whilst voluminous, unfortunately provides little guidance to forecasters on the long-run prospects for mortality, and because Australian age-specific deaths rates exhibit roughly constant exponential decline over the period 1971-2002. The forecasts were calculated as follows. Taking age-and sex-specific death rates calculated for the 1971-2002 period, we computed three year average death rates for 1971-73 and 2000-2002. These schedules were extended to age 120 by fitting and extrapolating the Kannisto version of the logistic model (Thatcher et al. 1998). The mortality age schedules were then smoothed and the annual average exponential rates of decline were calculated. The age patterns of these rates of decline were themselves smoothed and a small adjustment was made for males in the late 20 s and early 30 s to change a small annual increase in death rates to a small decrease. This reflects our optimistic view that the rise in young adult male mortality from self-harm and accidents will reverse. Using these smoothed annual average decreases we extrapolated out to 2051, finding 2050-51 $\mathrm{e}_{0}$ values of 87.7 years for males and 92.1 years for females. Figure 5 shows the predictive distributions for male and female $\mathrm{e}_{0}$. 


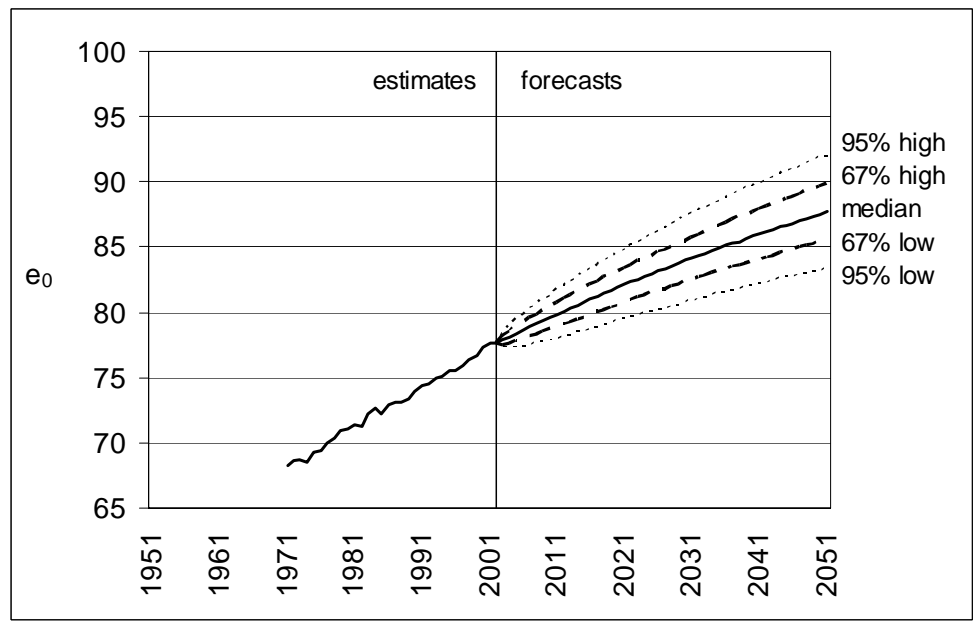

(a) males

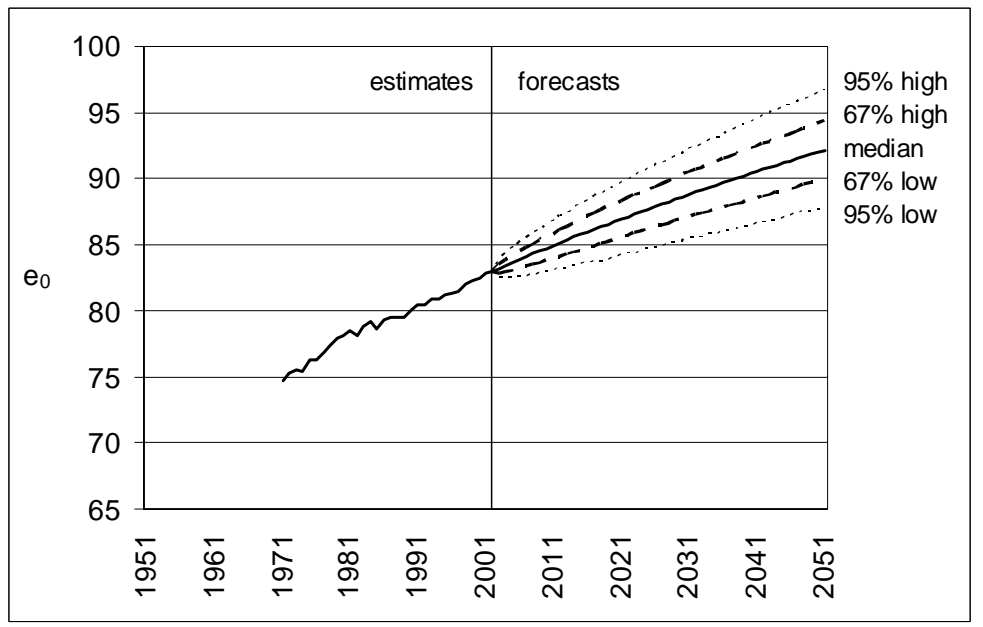

(b) females

Figure 5: $\quad$ Estimated life expectancy at birth and prediction interval bounds

Source of estimates: calculated from Australian Bureau of Statistics data 


\subsection{International migration}

For international migration we were initially faced by the decision of which method of incorporating migration into the cohort-component model to use. Should net migration be modelled, or immigration and emigration separately? If so, should immigration and emigration be disaggregated by population category, such as permanent and long-term? And are rates or numbers better? (McDonald and Kippen 2002).

The use of net migration numbers in the cohort-component calculations is appealing because of low data requirements (past net international migration trends can be computed as the residual of population change minus natural change) and the need to consider immigration-emigration correlations is also avoided. However, there are a number of conceptual and practical limitations to this approach.

(i) From a conceptual standpoint there is no such thing as a net migrant (Rogers 1990). While models by definition incorporate only the main elements of a system, it is argued that just modelling net migration is too great a simplification of real world processes. In the same way that it would be unsatisfactory to model natural change directly rather than as the result of separate fertility and mortality processes, migration is best modelled by reference to both immigration and emigration.

(ii) The use of net numbers of migrants in a cohort component model can potentially generate nonsensical negative populations for some age groups. In forecasts for Australia this problem will be rare because net migration age profiles contain positive net migration figures or small negative figures. In other countries, however, where some probabilistic net migration sample paths are highly negative for the entire forecast horizon then this issue is likely to arise.

(iii) The use of fixed age schedules of net migration presents at least two substantial problems in probabilistic forecasting. First, it prevents international migration from responding to the population's evolving age profile. As a population ages one would expect the net migration age profile to respond to the changing age composition of the population. Second, it fails to incorporate the wide variations in the net migration age profile that result from different levels of immigration and emigration. This is less of an issue in deterministic forecasts in which total net migration is often held constant over time, but in a probabilistic forecast in which there are substantial variations in immigration and emigration a fixed age schedule of net migration cannot be justified. To illustrate this, Figure 6 shows the predictive distribution of the age profile of net migration for the final year of our forecasts.

In the light of these concerns, an obvious alternative would be to model immigration and emigration separately. In fact, Australian migration statistics allow us to do better than this, as they distinguish between permanent and long-term migration. These data are sourced from arrival and departure cards completed by all arriving and 
departing passengers at airports and ports. Classification into permanent and long-term categories is based on self reported status of intended stay and visa category. Permanent immigrants are identified as arrivals who hold migrant visas, regardless of stated period of intended stay. Permanent emigrants consist of permanent residents who on departure state that they intend to settle permanently in another country. Long-term arrivals comprise Australian residents returning after a year or more overseas, together with overseas visitors stating they intend to spend a year or more in Australia. Long-term departures comprise Australian residents leaving the country for a year or more (but not permanently) and overseas visitors who have been in Australia for a year or more, now departing. New Zealand citizens receive special treatment in the migration statistics. They are free to live and work in Australia without being required to obtain permanent residence status, and will be classified as either as permanent or long-term migrants depending on what they state on their arrival or departure cards.

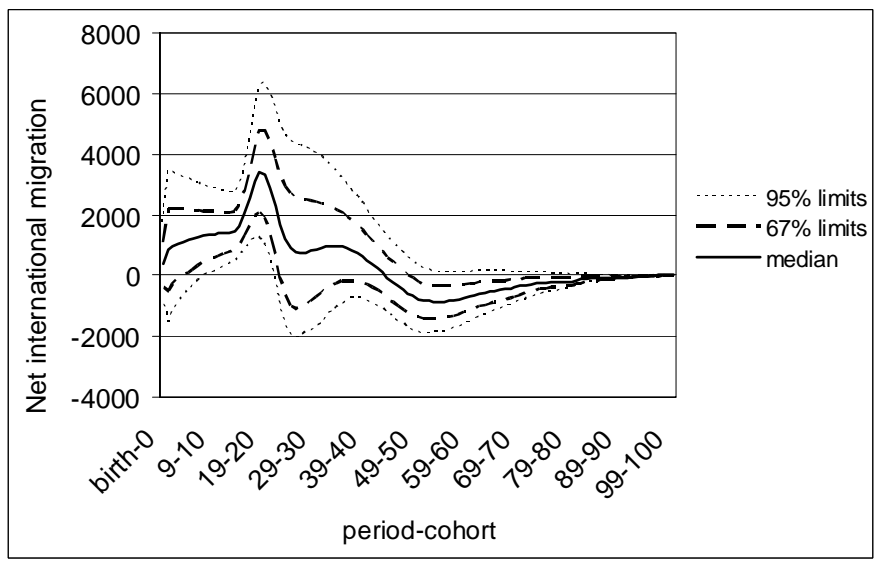

Figure 6: $\quad$ Predictive interval bounds of the net migration age profile, 2050-51

Note: above age 100 international migration was assumed to be zero. 
The permanent/long-term distinction permits the different characteristics and changing relative importance of the two migration types to be taken into account. Longterm migration has increased substantially since the 1980s, driven in large part by international student migration and the flows of skilled transients (Hugo 1999). At the same time permanent immigration has fluctuated around a linear trend. These two types of migration are also characterised by quite different age-sex profiles, with long-term migration being more concentrated in the young adult ages and permanent migration consisting of relatively more migrants in the childhood and older adult age groups (see Figure 11). So to more accurately reflect the contemporary structure of Australia's international migration system we chose to model four separate flows:

(i) permanent immigration,

(ii) permanent emigration,

(iii) long-term immigration, and

(iv) long-term emigration.

The question of whether migration rates or flows should be used is one that is rarely considered (though see Rees 1989, McDonald and Kippen 2002, Withers 2002). For immigration (both permanent and long-term), rates are problematic. Which population at risk should be used - the rest of the world or just the population of those countries which supply most of Australia's migrants? Yet forecasting immigration as a function of other countries' population sizes is difficult to justify given that international migration is influenced so much by factors such as migration policies, major world events, economic conditions and family ties. It could be argued that Australia's population should be used as the population "at risk" because of its role as a crude indicator of employment opportunities and family reunion migration. This type of "rate", however has the danger of forecasting ever increasing numbers of immigrants a danger which is particularly relevant to probabilistic modelling in which some sample paths of rates would be very high. In addition, for permanent immigration, past data do not show it rising in line with population, and the government's Migration Program is formulated in terms of numbers. We have therefore used numbers for both permanent and long-term immigration.

For permanent emigration, the use of rates rather than numbers seems sensible as it relates the amount of emigration to the size of the population at each age and ensures that the number of emigrants does not exceed the available population. However, past data on permanent emigration from Australia fail to show a clear relationship with population size (Figure 7) so we opted for the simpler option of forecasting total permanent emigration numbers. This also gives net permanent migration forecasts which fit well with past trends. In forecasting age-specific emigration, however, we initially applied base year age-specific rates to the population and then scaled the initial emigration numbers to match to specified total. This approach allowed emigration to be 
influenced by the changing shape of the population age profile and thus lowered the risk of emigrating out more people in any particular age group than there were available. Long-term emigration was also modelled in terms of numbers because of the way in which it was modelled via net long-term migration and long-term immigration (described below).

In modelling the sample paths for the four migration streams an attempt was made to reflect the nature of each migration flow and the correlations between them. All migration models were fitted to data from 1959 (the first year for which permanent and long-term migration are identified separately) to 2002. An $\operatorname{ARIMA}(1,1,0)$ model was found to fit permanent emigration well:

$$
P E(T)=P E(T-1)+\phi_{P E}[P E(T-1)-P E(T-2)]+\varepsilon_{P E}(T)+c_{P E}(T)
$$

where 'PE' denotes 'permanent emigration' and the other terms are defined as before. The $\phi_{P E}$ and $\varepsilon_{P E}$ values are listed in Table 1. Permanent immigration, however, was found to be represented best by a simple ARIMA $(1,0,0)$ model:

$$
P I(T)=\phi_{P I} P I(T-1)+\varepsilon_{P I}(T)+c_{P I}(T)
$$

where 'PI' denotes 'permanent immigration' and the other terms are defined as before. Parameter values are given in Table 1 . In addition to providing a good fit to past data an autoregressive model without differencing also suits permanent immigration from a conceptual viewpoint. Whilst this model can generate large fluctuations from the median the predictive intervals cease widening after just a few years, reflecting the strong pull of the median of the distribution, or rather, the strong influence of Australian government migration policies on this migration stream. Permanent immigration consists of migrants granted visas through the Migration and the Humanitarian Programs arriving in Australia, as well as New Zealand citizens migrating permanently. For most categories of visa in the Migration Program, and for the Humanitarian Program, there are limits to the numbers of visas issued each year. Despite this influence from government policy, there are quite substantial year to year fluctuations in the permanent immigration figures. This is partly due to fluctuations in the size of the immigration program, but it also reflects delays between visa issue and date of arrival as well as visa-free Trans-Tasman movement. Past trends suggest, at best, weak links between permanent immigration and permanent emigration so they were assumed to be independent in the modelling.

Long-term immigration and emigration trends, however, are strongly correlated. This is to be expected given that these flows consist of foreign students and skilled 
workers migrating temporarily to Australia for study or employment, and flows of Australian citizens and permanent residents going overseas for a few years. In constructing a model for these two flows we kept in mind that the future of long-term migration is quite uncertain. It is not yet clear whether the recent rise in long-term migration is a shift to a new level, or whether it represents the beginning of a long-run increase (Hugo 1999). This uncertainty suggested wide predictive distributions, but with a fairly close correspondence between long-term immigration and emigration, thus giving a net long-term migration predictive distribution that is considerably narrower. A three-stage process was used to achieve this.

(1) First, long-term immigration was modelled. We found that an $\operatorname{ARIMA}(3,1,0)$ model was appropriate in this case:

$$
\begin{aligned}
\operatorname{LTI}(T)= & \operatorname{LTI}(T-1)+\phi_{1, L T I}[\operatorname{LTI}(T-1)-\operatorname{LTI}(T-2)] \\
& +\phi_{2, L T I}[\operatorname{LTI}(T-2)-\operatorname{LTI}(T-3)] \\
& +\phi_{3, L T I}[\operatorname{LTI}(T-3)-\operatorname{LTI}(T-4)]+\varepsilon_{L T I}(T)+c_{L T I}(T)
\end{aligned}
$$

where 'LTI' is for 'long-term immigration' and the other terms are defined as before. Parameter values are shown in Table 1.

(2) Second, long-term net migration was modelled as an $\operatorname{ARIMA}(1,0,0)$ process:

$$
\operatorname{LTN}(T)=\phi_{L T N} \operatorname{LTN}(T-1)+\varepsilon_{L T N}(T)+c_{L T N}(T)
$$

where 'LTN' denotes 'long-term net migration'. Again, parameter values are given in Table 1. Because of the correlation between the error values for long-term immigration and net long-term migration $(\mathrm{r}=0.714)$ correlated random errors were generated via Cholesky decomposition. A small number of sample paths (about 100) were rejected and replaced because they contained long-term immigration and net migration values which implied negative long-term emigration.

(3) Finally, long-term emigration was calculated simply as long-term immigration minus long-term net migration. We emphasise that long-term net migration was modelled only as part of the process of generating long-term emigration. It was not input into the cohort component model.

Although the international migration models described above are non-trivial, probably the greatest challenge in implementing the migration component of the 
probabilistic forecasts was the assumption setting. International migration statistics for Australia, particularly in recent years, are thought to have become quite unreliable (Khoo and McDonald 2000, McDonald et al. 2003, ABS 2003b). In fact, when supplying the authors with international migration data the ABS strongly advised against drawing any conclusions from the data for 1997 onwards. In all graphs, therefore, 1997-2002 data are shown with dashed lines to represent this health warning.

The problems with the data stem from the incorrect categorisation of migrants, and double counting. The most puzzling phenomenon of recent years is a huge increase in long-term immigration without the expected increase in long-term emigration. McDonald et al. (2003) suggest that this discrepancy is due to a number of factors. First, there are long-term immigrants who convert to permanent residence whilst in Australia (these migrants should then be re-classified in the international migration statistics to permanent immigrants, though this does not currently occur). Second, there is a tendency for some people who state on arrival in Australia that they intend to stay for exactly one year (and are therefore long-term immigrants) to leave just short of one year (so should really be classified as short-term visitors). Third, some double counting occurs. For example, foreign students and workers who return home for a short visit to their home country part-way through their studies or employment contract will leave Australia classified as a short-term visitor (ABS 2003b). When they return a week or two later they may have more one year still to complete in their studies/employment and will indicate this on their arrival passenger card, and therefore be counted as a longterm immigrant (again). In response to these difficulties the ABS recently instituted a new method of estimating international migration flows which deals with many of these problems (ABS 2003b). However, these newly-estimated figures are only available from mid-2001 onwards so the assumptions required for these forecasts must make use of the old, less reliable data. Furthermore, the new method does not solve all of the problems mentioned above (for details see ABS 2003b). 


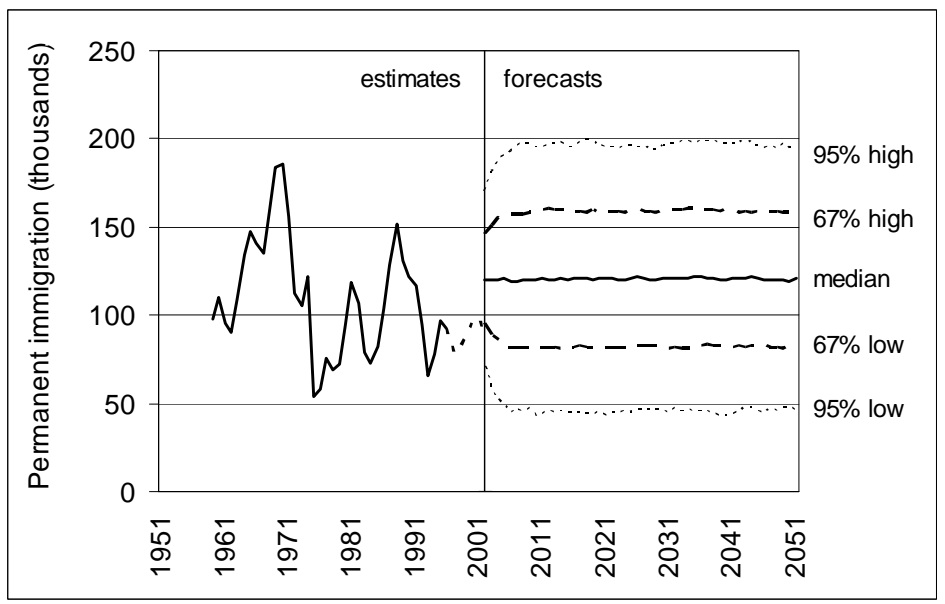

(a) Permanent immigration

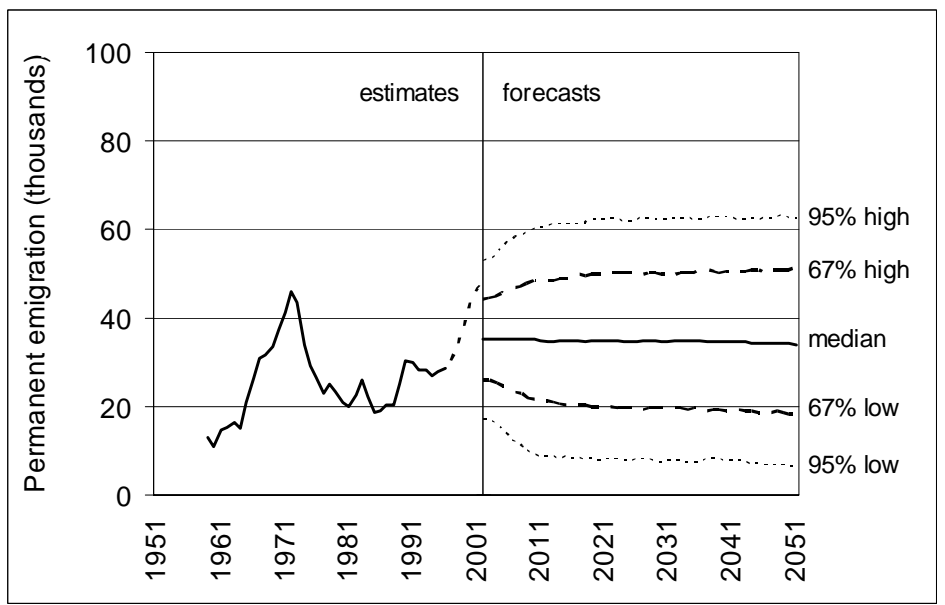

(b) Permanent emigration

Figure 7: $\quad$ Estimated permanent migration and prediction interval bounds 


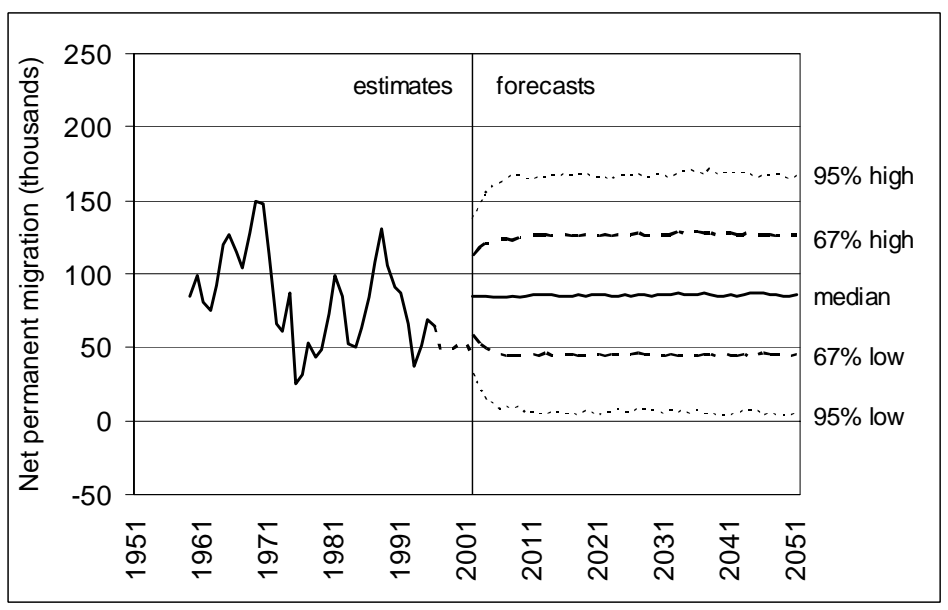

(c) Net permanent migration

Figure 7: (Cont.) Estimated permanent migration and prediction interval bounds

Source of estimates: Australian Bureau of Statistics

Notes: (1) As discussed in the text, the permanent immigration estimates are thought to be too low due to the exclusion of long-term migrants who convert to permanent residence whilst in Australia (who should then be re-classified as permanent immigrants).

(2) Dashed lines for 1997-2001 denote data thought to be particularly unreliable, as advised by the Australian Bureau of Statistics.

We now turn to the migration forecast assumptions. For permanent immigration we set the median trend at 120,000 per year for the course of the projections. This consists of a government Migration Program of 105,000 per year, a Humanitarian program of 10,000 per year and a long-run annual average gain of 5,000 New Zealanders. Ceiling and floor limits of $\pm 120,000$ were applied to the permanent immigration error forecasts. For permanent emigration we chose a median figure of 35,000 per year, with ceiling and floor limits $\pm 35,000$. Because of the uncertainty of recent migration statistics, probabilistic jump-off year values were selected. The widths of these jump-off error distributions for permanent immigration and emigration were estimated by running the model without any jump-off errors for 2002-2007, equivalent to starting the migration simulations in 1997. This makes the bold assumption, of course, that the migration figures were accurate until 1997. The predictive distributions for the two permanent migration streams are shown in Figure 7. 
We assumed that long-term migration would continue to grow in importance so we set the long-term immigration trend to grow by 3,000 per year. This is an arbitrary figure but reflects an expectation that in an increasingly inter-connected world longterm migration will increase in intensity. A net gain of 15,000 per year was set, indicating an expansion of the temporary resident population. Given the great uncertainty about the direction of long-term immigration and emigration we allowed wide predictive distributions for these two migration streams. Ceiling and floor limits for long-term immigration were set at zero and twice the set trend, whilst for net longterm migration sample paths that implied negative long-term emigration when combined with the long-term immigration figures were rejected. For estimating the jump-off year uncertainty the approach used for permanent migration produced a jumpoff distribution for long-term immigration where the recently observed suspect figures lay well above the upper $95 \%$ limit. This seemed unsatisfactory so we used guesstimates instead. Relevant parameters are given in Table 1. The predictive distributions for long-term migration are shown in Figure 8 and the combined permanent and long-term predictive distributions are shown in Figure 9.

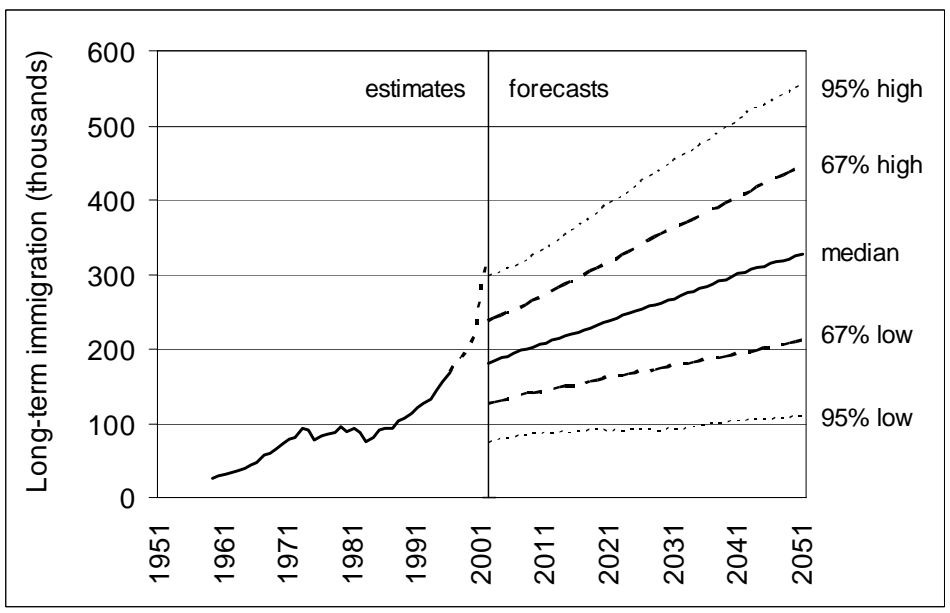

(a) Long-term immigration

Figure 8: $\quad$ Estimated long-term migration and prediction interval bounds 
Demographic Research - Volume 11, Article 8

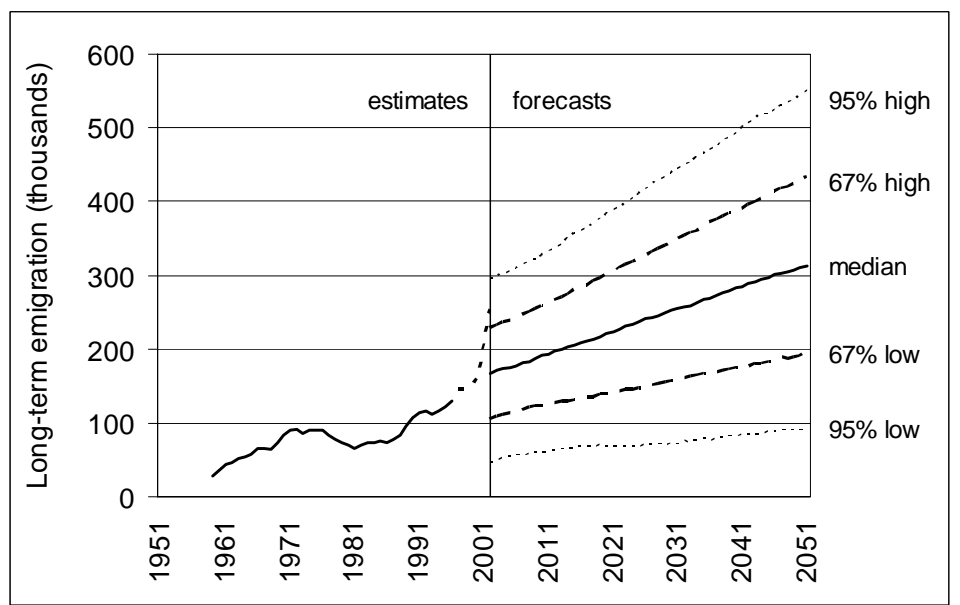

(b) Long-term emigration

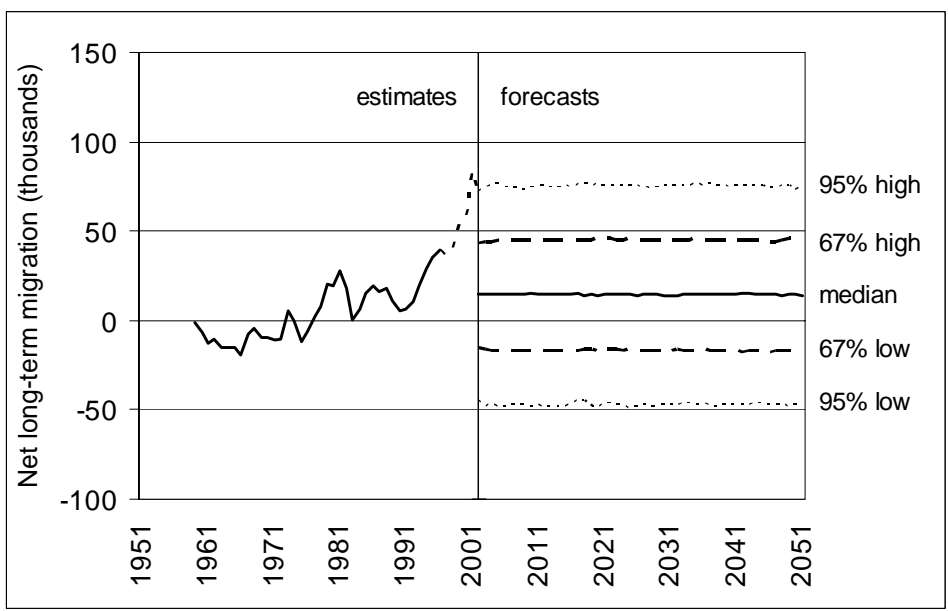

(c) Net long-term migration

Figure 8: $\quad$ (Cont.) Estimated long-term migration and prediction interval bounds

Source of estimates: Australian Bureau of Statistics

Notes: (1) As discussed in the text, the long-term immigration estimates are thought to be too high due to the inclusion of short-term visitors (who, because they are in Australia for less than one year, should not be classified as migrants) and long-term migrants who convert to permanent residence whilst in Australia (who should then be re-classified as permanent immigrants).

(2) Dashed lines for 1997-2001 denote data thought to be particularly unreliable, as advised by the Australian Bureau of Statistics. 
Demographic Research - Volume 11, Article 8

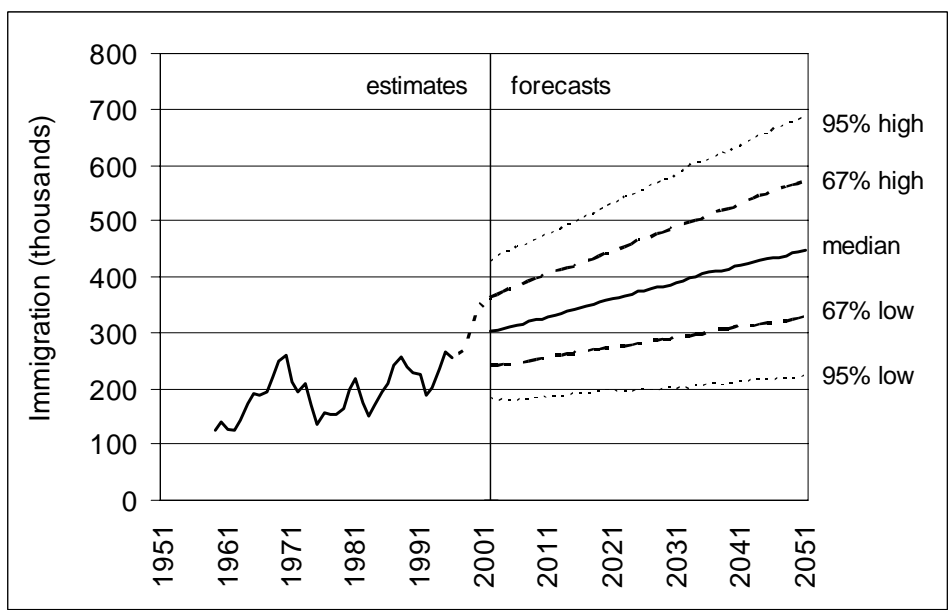

(a) Permanent and long-term immigration

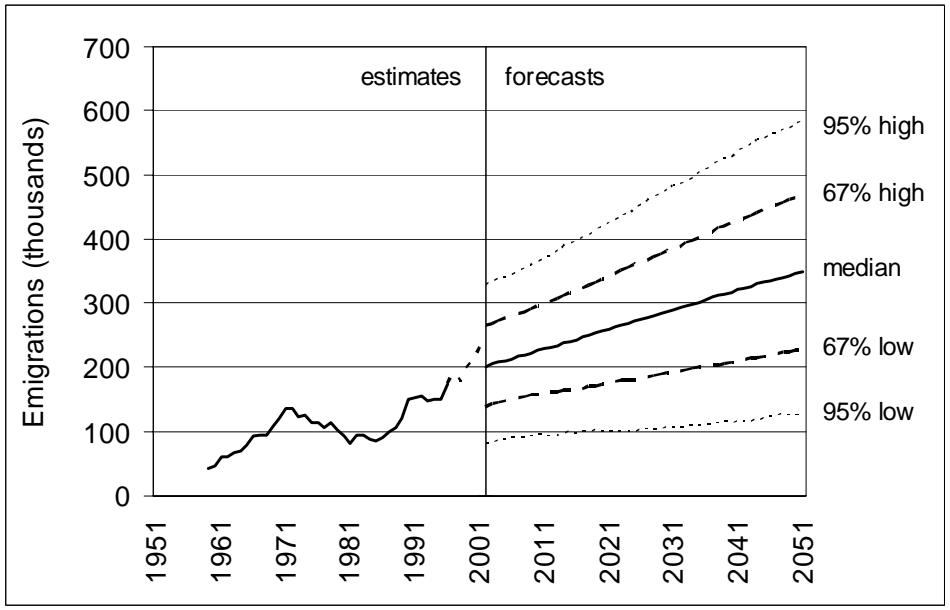

(b) Permanent and long-term emigration

Figure 9: $\quad$ Estimated permanent and long-term migration and prediction interval bounds 


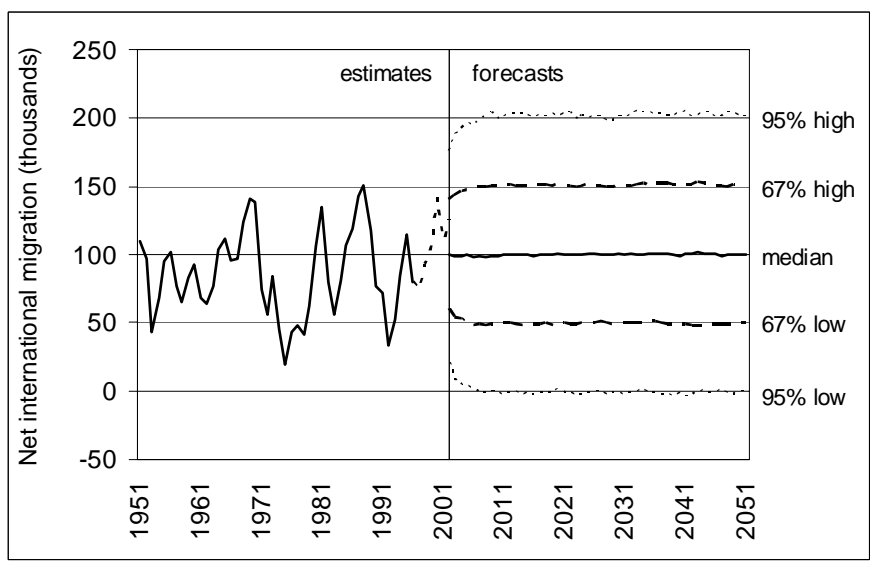

(c) Net permanent and long-term migration

Figure 9: (Cont.) Estimated permanent and long-term migration and prediction interval bounds

Source of estimates: Australian Bureau of Statistics

Note: Dashed lines for 1997-2001 denote data thought to be particularly unreliable, as advised by the Australian Bureau of Statistics.

Before the parameters of the migration models were finalised a comparison with past ABS net international migration forecast errors was made (comparisons of immigration and emigration errors were not possible as the ABS projection model uses net migration only). These errors are shown in Figure 10. The net international migration predictive distribution (Figure 9c) has a standard deviation of about 53,000 from just three years into the forecast horizon, after which it remains about constant. The standard deviation of the past errors three years into the forecasts is 44,000 and between 40-50,000 thereafter. This suggests that our predictive distribution is a fraction too wide but in light of the recent migration data reliability problems we decided not to make any adjustments.

The international migration age profiles were provided by parameterised model migration schedules (Rogers et al. 1978), and these are shown in Figure 11. Because of the ABS' health warning about the quality of recent migration data we decided to base these model schedules on an average of 1993-96 figures. 


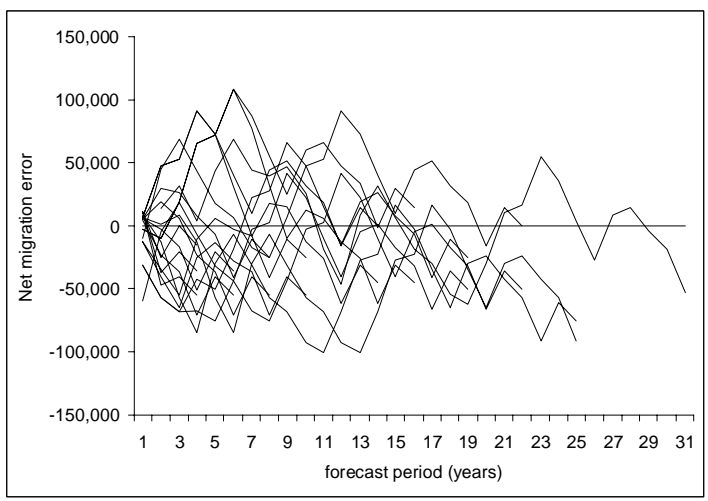

\section{Figure 10: Past ABS net international migration forecast errors}

Source: calculated from Australian Bureau of Statistics population projections for jump-off years 1970, 1976, 1978, 1981, 1984, 1987, 1989, 1993, 1995, 1997 and 1999 and net migration figures calculated by the residual method using population estimates, births and deaths.

Note: jump-off year errors (forecast period of zero) are not shown because not all ABS projection volumes reported the relevant net international migration figure.

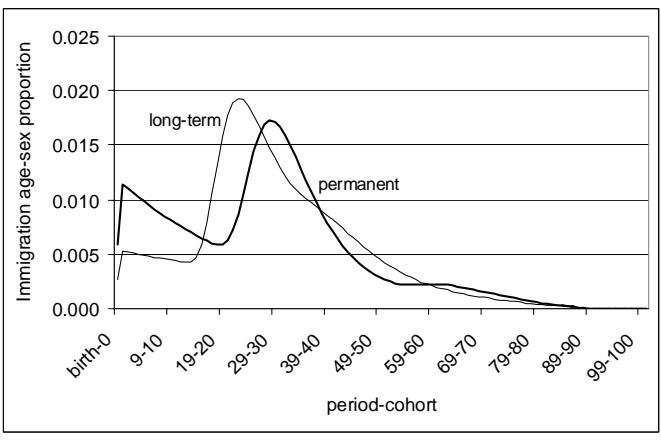

(a) Male immigration

Figure 11: Parameterised model migration schedules for male and female permanent and long-term immigration and emigration 


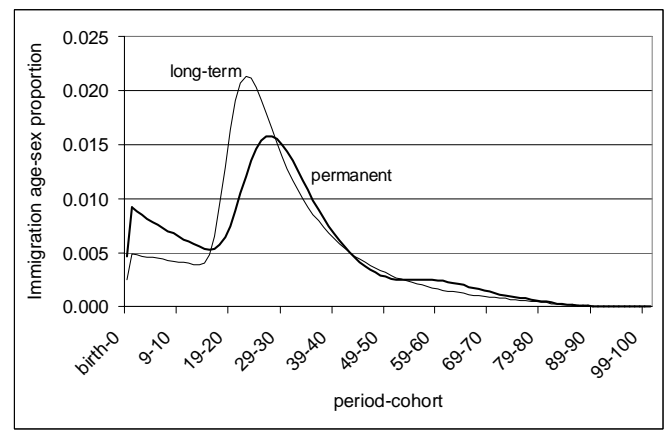

(b) Female immigration

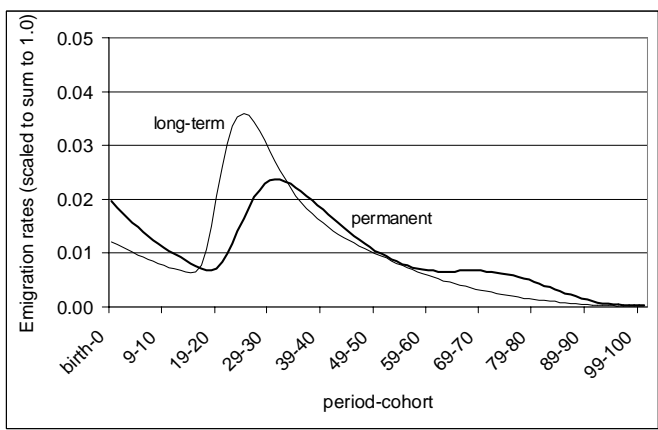

(c) Male emigration

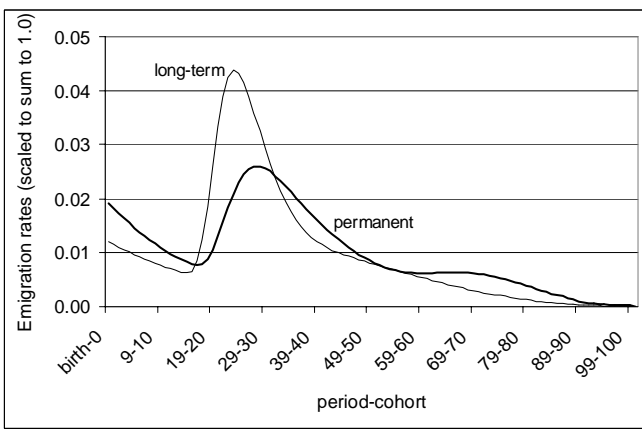

(d) Female emigration

Figure 11: (Cont.) Parameterised model migration schedules for male and female permanent and long-term immigration and emigration

Note: above age 100 international migration was assumed to be zero. 


\section{Results}

\subsection{Total populations}

Figure 12 presents the forecast distribution for the total population of Australia for 2002-2051. The median population forecast for 2051 is 28.0 million, with the two thirds probability range covering 24.4 to 31.8 million, an interval equal to $26 \%$ of the median forecast. The $95 \%$ probability range in 2051 extends from 21.1 to 36.0 million.

If Australia's population follows the median of the forecast distribution this will represent a $42 \%$ increase in population over the 2002-51 period, a sizeable proportion of which will be due to population momentum. As shown in Figure 16(a) the age structure of Australia's population does not suffer from the undercut profile characteristic of low-fertility countries, which, with a TFR of 1.70 and when supplemented by immigration, should ensure a plentiful supply of future parents and births. To isolate the contribution of Australia's age structure to future population growth we prepared a forecast with replacement fertility (a TFR of 2.075), life expectancy held constant, and no migration. This gave a 2051 population of 22.2 million, demonstrating that of the 8.3 million increase in the country's population from 2002-51 according to the median forecast, $31 \%$ will be the result of positive momentum. This situation is in stark contrast to many low fertility countries and the European Union as a whole where momentum has become negative (Lutz and Scherbov 2003, Lutz et al. 2003b).

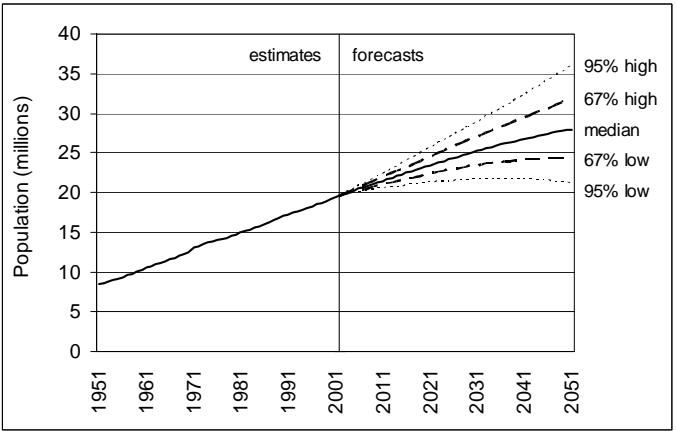

Figure 12: Estimated total populations and prediction interval bounds

Source of estimates: Australian Bureau of Statistics

Note: The slight discontinuity observed in 1971 is due to the change in the population definition from census counts of persons present to usually resident population estimates. 
We now turn to see how our forecasts compare with (i) the application of the National Research Council's (2000) ex post method to our median forecast, and (ii) the official population projections for Australia prepared by ABS. The National Research Council's ex post method suggests that the 95\% predictive interval for Australia 50 years after the jump-off year spans 0.7040 to 1.4205 of the point forecast (calculated from National Research Council 2000: Table F-3). Taking the median 2051 forecast of 28.0 million as the point forecast (and ignoring the fact this is only 49 years out) we obtain a $95 \%$ range of 19.7 to 39.8 million.

The ABS prepared a large number of variants in its 2002-based set of projections (ABS 2003a), though most prominence is given to three variants - labelled Series A (high), Series B (medium) and Series C (low). Although it is pointed out that "these projections are not intended as predictions or forecasts" (ABS 2003a: 1) most users, understandably, consider the medium variant as the most likely population future. This variant puts Australia's population at 24.0 million by 2026 and 26.4 million in 2051, a little lower than the 24.4 and 28.0 million medians of the total population forecast distribution for 2026 and 2051 that we forecast. The difference is due to both higher fertility and higher life expectancy at birth in our forecasts.

In presenting their projection results the ABS "uses Series $A$ and $\mathrm{C}$ to show a range, although not the full range, of the projected populations" (ABS 2003a: 31). Where does this high-low range lie on the total population predictive distribution as presented in Figure 12? This is a difficult question to answer because it varies year by year. In 2011 the range is from 21.1 million (series C) to 21.9 million (series A) which covers $63 \%$ of our predictive interval for this year. Moving on to 2026, the range extends from 22.8 million (series C) to 25.7 million (series A), encompassing $69 \%$ of possible outcomes according to our forecasts. By 2051, it has expanded to between 23.0 million (series C) and 31.4 million (series A), covering $73 \%$ of our predictive distribution. The inconsistency of the deterministic variants approach to uncertainty is thus clearly demonstrated.

\subsection{Components of population change}

Future total populations are of course influenced by the future paths of the demographic components of change. The international migration predictive distributions which formed part of the forecast inputs have already been discussed; here the forecast distributions for births, deaths and natural change are examined. Predictive distributions for births and deaths are shown in Figures 13 and 14. 


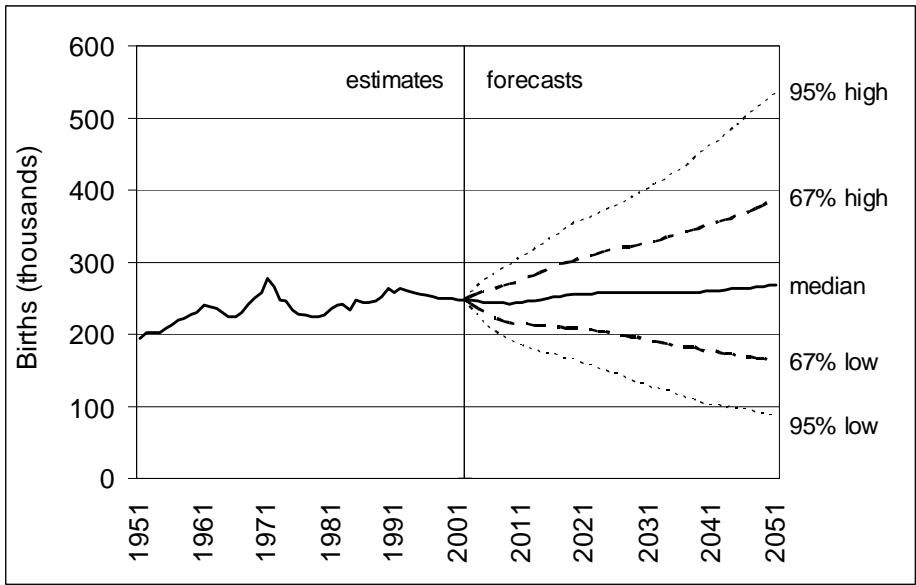

Figure 13: Recorded births and prediction interval bounds

Source of estimates: Australian Bureau of Statistics

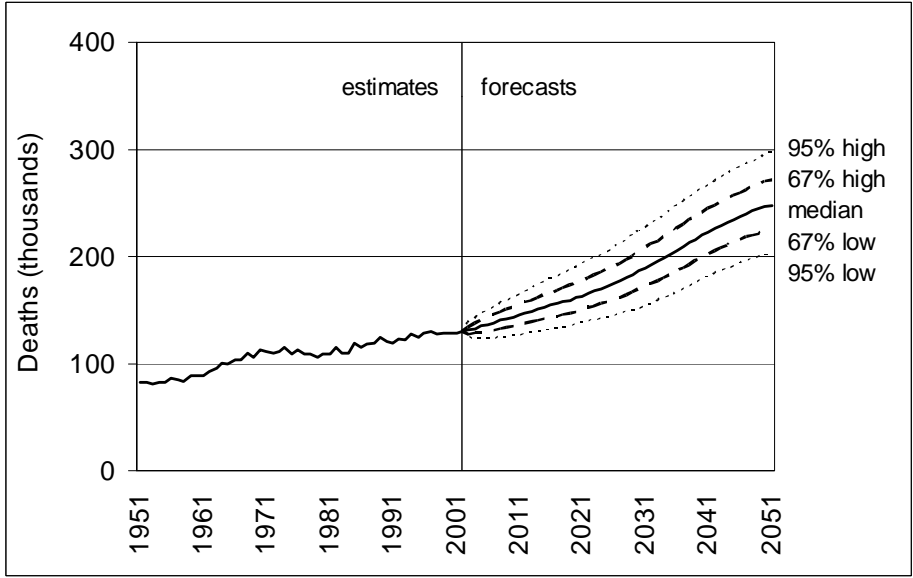

Figure 14: Recorded deaths and prediction interval bounds

Source of estimates: Australian Bureau of Statistics 


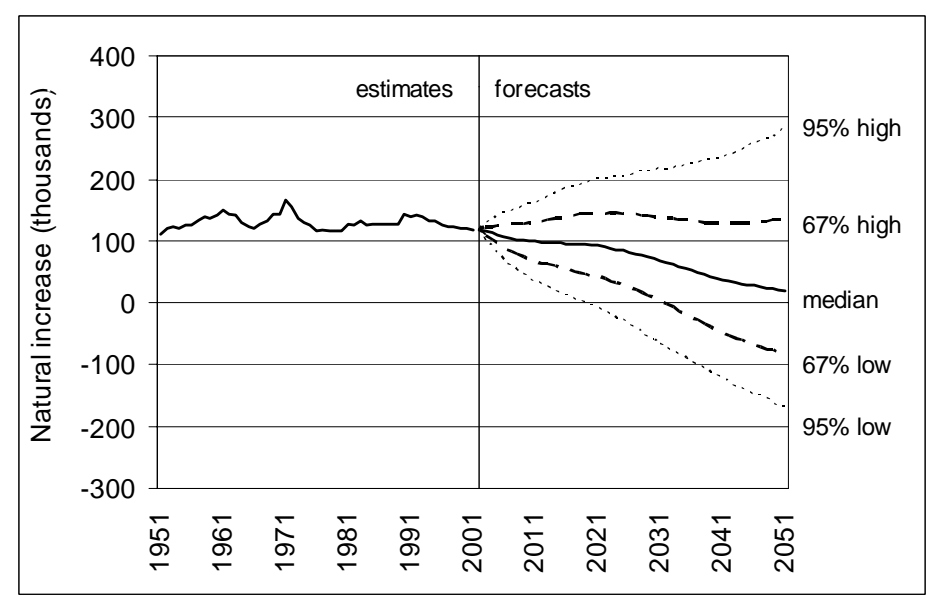

Figure 15: $\quad$ Natural increase and prediction interval bounds

Source of estimates: calculated from Australian Bureau of Statistics data

Australia's future with respect to births looks bright, with relatively little change from the numbers of births recorded in recent years according to the median of the distribution. McDonald and Kippen (1999: 4) make the useful point that large variations in Australia's age structure "can mean that demand for public services such as education and health services also fluctuate. As these services can involve substantial infrastructure and training costs ... it is more efficient to try to avoid widely fluctuating age structures". If the trend in births roughly follows the median of the predictive distribution then this desirable outcome will be achieved. Of course, it may not. The graph plainly shows that there is very considerable uncertainty surrounding the number of births, more than might be expected from looking at trends over the last 50 years, and this uncertainty continues to increase significantly over the forecast horizon. Why is this? The answer is that uncertainty is cumulative over the generations: from about 20 years into the forecasts some births are being produced by mothers not born in 2002, so there is increasing uncertainty in both the TFR and the size of the childbearing age population from about this time.

The future numbers of deaths are much more certain. This is partly due to the narrower forecast distributions for $\mathrm{e}_{0}$, and partly because most deaths over the forecast horizon occur to people already alive. The uncertainty of immigration and emigration, which is concentrated in the young adult ages (Figure 11), starts to contribute to the 
uncertainty over deaths when the cohorts which passed through the peak migration ages early in the forecast period reach the elderly ages in mid-century.

The net effect of births and deaths, natural increase, is displayed in Figure 15. This reveals that in the near future the surplus of births over deaths is likely to dip below 100,000 for the first time in over 50 years. With the coming rise in the number of deaths the contribution of natural increase to population change looks set to decline substantially, though by mid-century it is still likely to be positive. Whilst this huge decline in natural increase may alarm some commentators, it should be noted that in many other industrialised countries natural increase by this time will be highly negative; indeed in a few countries the switch from positive to negative natural increase has already taken place (United Nations 2003).

\subsection{Age-sex structures}

Figure 16 illustrates how uncertainty in Australia's age-sex structure unfolds over the forecast horizon. In the first few years of the forecasts the relatively high uncertainty surrounding the numbers of births results into fairly wide predictive intervals in the youngest childhood age groups whilst the uncertainty over international migration manifests itself mostly in the peak migration age groups of the younger adult ages (Figure 16b). By 2021 (Figure 16c) these cohorts have spread this migration uncertainty to higher ages, whilst the two decades of uncertainty over births can be seen clearly in the fan shape at the bottom of the pyramid. The lower uncertainty over mortality takes longer to become evident in the age-sex structure, though by 2031 (Figure 16d) it has started to become apparent in the elderly ages. Beyond this time the pattern of uncertainty across age groups changes little but continues to widen (Figure 16e and f). Notice how the predictive distribution at the childhood ages by mid-century mirrors that of births (Figure 13).

We now briefly focus on three broad age groups: 0-19, 20-64 and 65+. Figure 17 shows the predictive distributions for these age groups expressed as both numbers and percentages of the total population. Reflecting the median of the predictive distribution for births, Figure 17a reveals that the approximately stable number of 0-19 year olds which has existed for the last three decades is most likely to continue. Figure $17 \mathrm{~b}$ shows that as a percentage of the population, however, there is a little chance of this age group maintaining or increasing its share of the population total. Relative to the population in the working ages, as expressed by the Youth Dependency Ratio (Table 2), the dependency of children is most likely to decline.

Rather more certainty surrounds the future size of the working-age group population. Figure $17 \mathrm{c}$ suggests that this population group is most likely to continue 
growing throughout the forecast horizon, albeit it at a reduced rate. Interestingly, although the share of this age group in the population declines, it is unlikely to be much lower than it was in the early 1960s, thanks to a healthy number of births and immigrants.

Among the 65+ population there is absolutely no uncertainty about the direction of change, as revealed by Figure 17e. Significant population ageing is guaranteed (Figure 17f). There is almost $100 \%$ certainty that the current 2.5 million aged 65 and over will have expanded to more than 6 million by mid-century. The two-thirds probability for 2051 suggests 6.7 to 8.1 million people in this age group, with the median lying at 7.4 million. As a percentage of the total population the two-thirds probability ranges from $23.9 \%$ and $29.1 \%$ (Figure 17f). Although this represents a substantial change from the 2002 percentage of 12.7 , it is interesting to note this is quite a bit lower than the figures recently forecast by Lutz and Scherbov (2003) for the European Union (of 15 members before the recent expansion). For the $65+$ age group they give a 2050 median forecast of $30.8 \%$ with an $80 \%$ probability range of $26.8 \%$ to $35.5 \%$, up from $16.3 \%$ in 2000 . The equivalent figures for 2050 for Australia are 26.4\% (median) and $23.2 \%$ to 30.3\% ( $80 \%$ interval). Although it is very likely that the Elderly Dependency Ratio will be at least double its current value by mid-century, this will be partly offset by a decline in the Youth Dependency Ratio so that the overall Dependency Ratio increases by roughly a third (Table 2).

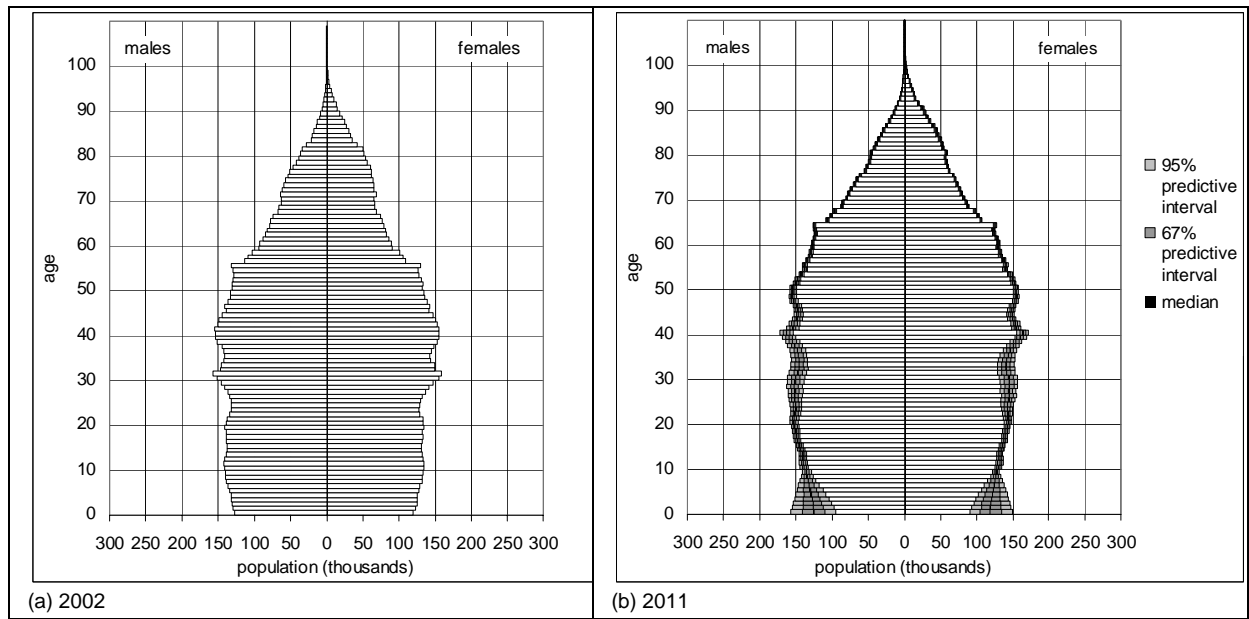

Figure 16: Jump-off year and prediction interval bounds of the age-sex structure for selected years 


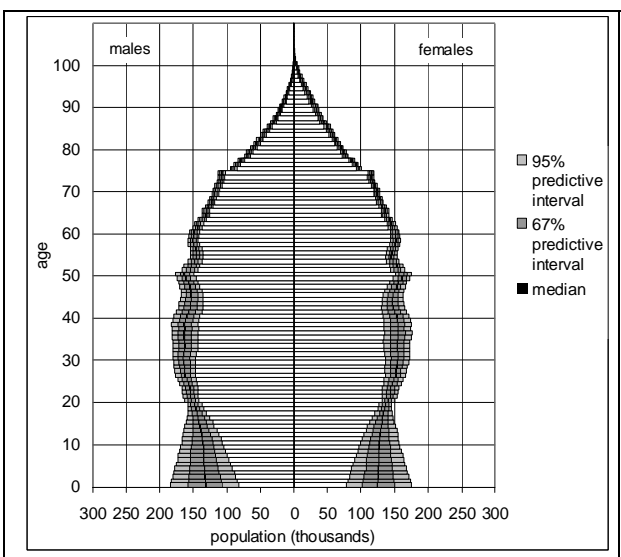

(c) 2021

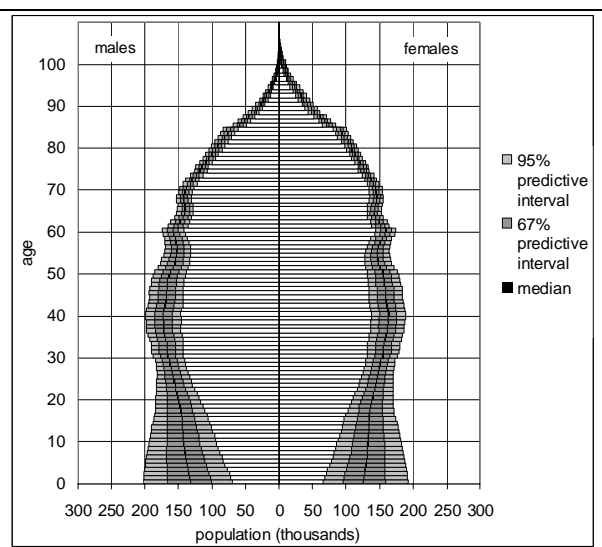

(d) 2031

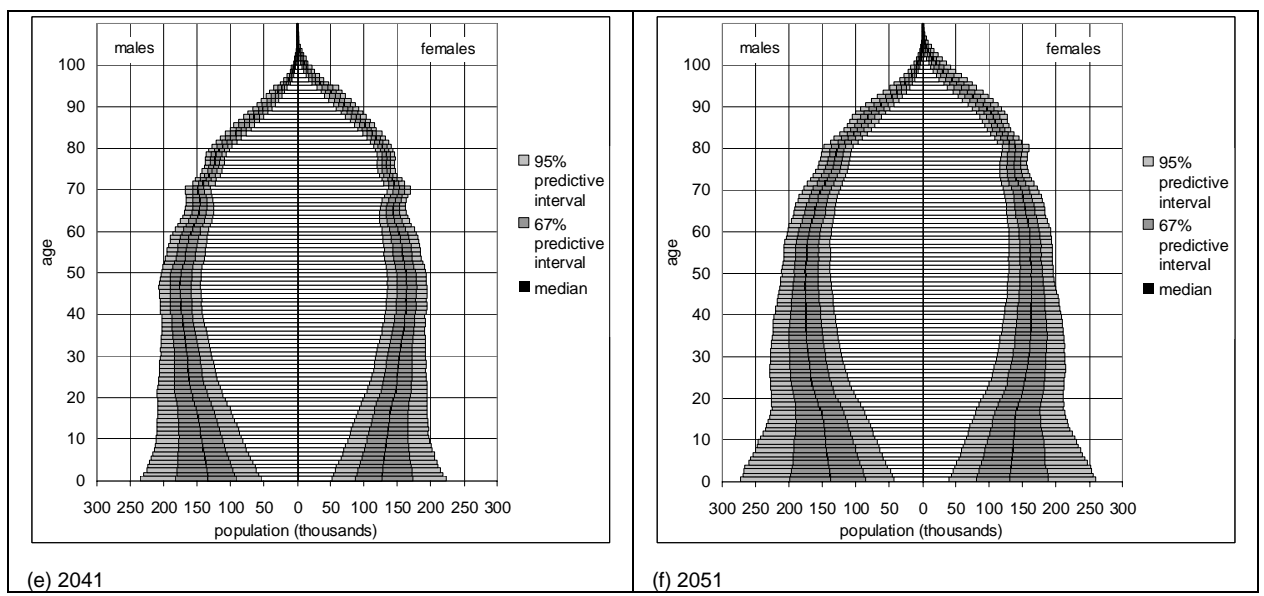

Figure 16: (Cont.) Jump-off year and prediction interval bounds of the age-sex structure for selected years

Source of 2002 estimates: Australian Bureau of Statistics 


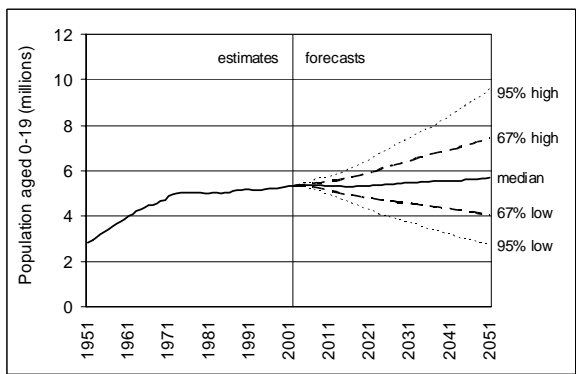

(a) 0-19

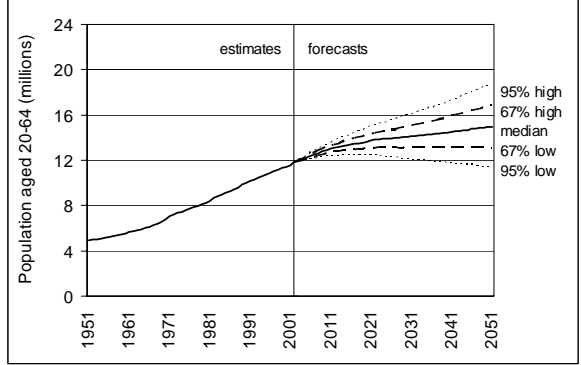

(c) 20-64

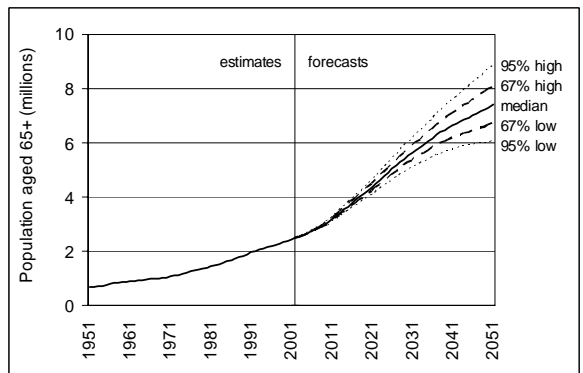

(e) $65+$

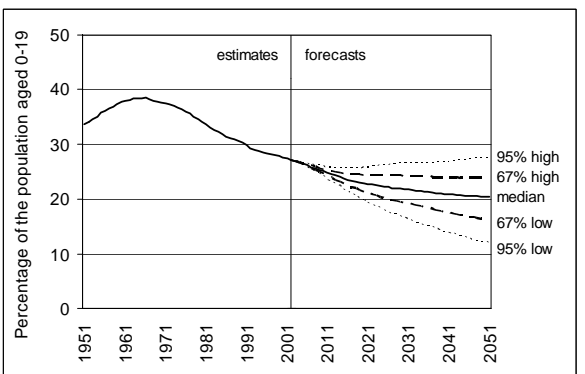

(b) percentage 0-19

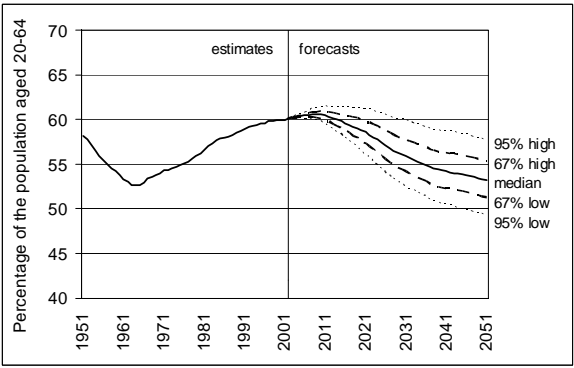

(d) percentage 20-64

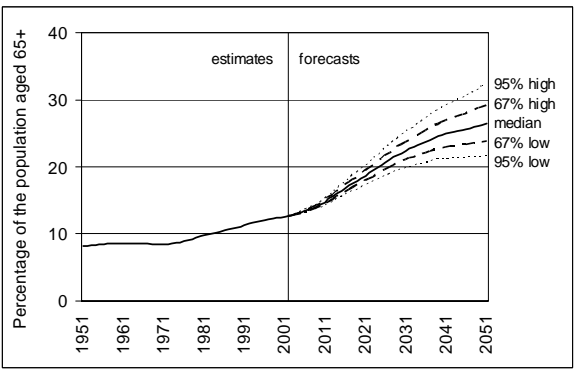

(f) percentage 65+

Figure 17: Estimated populations by broad age groups and prediction interval bounds

Source of estimates: Australian Bureau of Statistics

Note: The slight discontinuity observed in 1971 is due to the change in the population definition from census counts of persons present to usually resident population estimates. 
Table 2: $\quad$ Estimated and forecast distributions of the Dependency Ratios

\begin{tabular}{|c|c|c|c|c|c|c|c|}
\hline & 2002 & & 2026 & & & 2051 & \\
\hline & & $67 \%$ low & median & $67 \%$ high & $67 \%$ low & median & $67 \%$ high \\
\hline Youth & & & & & & & \\
\hline Dependency & 0.453 & 0.342 & 0.388 & 0.436 & 0.296 & 0.381 & 0.462 \\
\hline Ratio & & & & & & & \\
\hline Elderly & & & & & & & \\
\hline Dependency & 0.211 & 0.344 & 0.361 & 0.379 & 0.450 & 0.496 & 0.546 \\
\hline Ratio & & & & & & & \\
\hline $\begin{array}{l}\text { Dependency } \\
\text { Ratio }\end{array}$ & 0.664 & 0.701 & 0.750 & 0.799 & 0.805 & 0.879 & 0.949 \\
\hline
\end{tabular}

Source of 2002 estimates: Australian Bureau of Statistics

Note: The Youth Dependency Ratio is defined as those aged 0-19 divided by the population aged 20-64; the Elderly Dependency ratio is defined as the population aged $65+$ divided by those aged $20-64$.

\section{Conclusions}

In this paper we have presented the first comprehensive set of probabilistic population forecasts for Australia. Their probabilistic nature enables many of the shortcomings of deterministic variant forecasts - such as difficulties in interpreting the likelihood of high and low variants, and probabilistically inconsistent high-low ranges - to be overcome. The key results of our 2002-based forecasts include:

- a two thirds probability that Australia's population will lie between 24.4 and 31.8 million by 2051, with the median of the predictive distribution being 28.0 million (Figure 12);

- considerable uncertainty over births but a median forecast which suggests an approximately stable number each year (Figure 13);

- $100 \%$ certainty that the number of deaths will rise; by mid-century the annual number of deaths is most likely to be double the current number (Figure 14);

- an annual level of international migration which is unlikely to fluctuate outside the $0-200,000$ range (Figure 9c);

- a much older age structure, but according to the median forecast, one that we should not be unduly alarmed by (Figures 16 and 17, and Table 2).

Our principal methodological contribution has been to propose a method for forecasting international migration which takes into account the very different trends and age profiles of permanent and long-term international migration. Such a distinction is not only useful for assumption-setting, but also permits the strong correlation between long-term immigration and emigration to be disentangled from permanent 
immigration and emigration which are weakly correlated. To deal with the uncertainty over recent migration trends probabilistic distributions of jump-off year values were added. Furthermore, to better handle the populations at very advanced ages the age disaggregation of the cohort component model was extended beyond the normal 0-99 and $100+$ used in Australia to ages 0-119 with $120+$ as the final age group.

The last decade has been an exciting and productive time in the development of probabilistic population forecasting methods and applications. Indeed, the uncertainty of population forecasting has been the focus of a number of books and special issues of journals (for example, Lutz et al. 1999b, National Research Council 2000, Lutz et al. 2004, and most recently, the International Statistical Review volume 72, numbers 1 and 2). However, as Lutz and Goldstein (2004) have recently pointed out several challenges remain, both in terms of methods and in terms of the marketing of probabilistic forecasts to users and statistical offices. Amongst the many issues awaiting researchers' attention, of particular note to us is the extension of probabilistic methods to subnational population forecasting. A striking feature of nearly all probabilistic forecasting work to date is its focus on national or supra-national areas. But the addition of internal migration into the forecasting equation generally renders the population future of subnational areas more uncertain than at the national scale. The next stage of our research is to extend the model described in this paper to deal with internal migration in a multiregional framework.

\section{Acknowledgments}

This work was financially supported by a collaborative research agreement with the Queensland Government Office of Economic and Statistical Research. All views expressed in this article are those of the authors and do not necessarily represent the official position of the Queensland Government.

The authors would like to thank the anonymous reviewers for their many helpful comments on an earlier draft of this paper, and to Michael Roden of the Australian Bureau of Statistics who provided comments in a personal capacity. All errors, however, remain our own. 


\section{Notes}

1. Researchers using Australian mortality data face a number of problems. The earliest year for which population figures based on the usually resident definition are available is 1971. Prior to that only persons' present data are available, so mortality rates suffer a discontinuity at this point. In addition, up to the 1960s there is inconsistent coverage of indigenous people both over time and in the deaths counts and population figures for the same year. Furthermore, there are inconsistencies during the two World Wars, such as all deaths during World War 2 being dated as 1943. See Smith (2003) for an overview of these issues. 


\section{References}

Alho, J (2002) The population of Finland in 2050 and beyond. Discussion Paper no. 826, The Research Institute of the Finnish Economy, Helsinki.

Atkins, D (2004) “Go forth and multiply" The Courier-Mail, 12 May

Australian Bureau of Statistics (ABS) (2003a) Population projections Australia, 2002 to 2101. Canberra: Australian Bureau of Statistics.

Australian Bureau of Statistics (ABS) (2003b) Net overseas migration: adjusting for actual duration of stay or absence. Demography Working Paper 2003/5. http://www.abs.gov.au/

Australian Institute of Health and Welfare (AIHW) (2000) Australia's Health 2000. Canberra: AIHW.

Australian Labor Party (2004) "Labor's Baby Care Payment". Accessed 2 June 2004 from http://www.alp.org.au/dload/federal/media/baby_care_payment.pdf

Booth, H (2004) "On the importance of being uncertain: forecasting population futures for Australia." People and Place 12.2: 1-12.

Booth, H, Maindonald, J and Smith, L (2002) Applying Lee-Carter under conditions of variable mortality decline. Population Studies 56: 325-336.

Cohen, JE (1986) "Population forecasts and confidence intervals for Sweden: a comparison of model-based and empirical approaches." Demography 23: 105126.

De Beer, J and Alders, M (1999) "Probabilistic population and household forecasts for the Netherlands." Paper prepared for the joint ECE-EUROSTAT work session on demographic projections, Perugia, Italy, 3-7 May 1999.

Hugo, G (1999) "A new paradigm of international migration in Australia." New Zealand Population Review 25: 1-39.

Keilman, N (2001) "Data quality and accuracy of United Nations population projections, 1950-95." Population Studies 55: 149-164.

Keilman, N, Pham, DQ and Hetland, A (2001) Norway's Uncertain Demographic Future. Social and Economic Studies no. 105. Oslo: Statistics Norway.

Khoo, S and McDonald, P (2000) Category jumping: trends, demographic impact and measurement issues. Report to the Department of Immigration, Multicultural and Indigenous Affairs and the Australian Bureau of Statistics. 
Lee, R (1999) "Probabilistic approaches to population forecasting." In: Lutz W, Vaupel J W and Ahlburg D A (eds) Frontiers of Population Forecasting. Supplement to population and Development Review volume 24. New York: Population Council: 156-190.

Lee, R and Tuljapurkar, S (1994) "Stochastic population forecasts for the United States: beyond high, medium and low." Journal of the American Statistical Association 89: 1175-1189.

Lutz, W and Goldstein, JR (2004) "Introduction: how to deal with uncertainty in population forecasting?" International Statistical Review 72: 1-4.

Lutz, W and Scherbov, S (1998) "An expert-based framework for probabilistic national population projections: the example of Austria." European Journal of Population 14: 1-17.

Lutz, W and Scherbov, S (2003) Future demographic change in Europe: the contribution of migration. Interim Report IR-03-066, IIASA, Laxenburg, Austria.

Lutz, W, Scherbov, S and Sanderson, W (2003a) "The end of population growth in Asia.” Journal of Population Research 20.1: 125-141.

Lutz, W, O'Neill, BC and Scherbov, S (2003b) "Europe's population at a turning point." Science 299: 1991-1992.

Lutz, W, Sanderson, W and Scherbov, S (2001) "The end of world population growth." Nature 412: 543-545.

Lutz, W, Sanderson, WC and Scherbov, S (1999a) Expert-based probabilistic population projections. In: Lutz, W, Vaupel, JW and Ahlburg, DA (eds) Frontiers of Population Forecasting. Supplement to population and Development Review volume 24. New York: Population Council: 139-155.

Lutz, W, Vaupel, JW and Ahlburg, DA (eds) (1999b) Frontiers of Population Forecasting. Supplement to population and Development Review volume 24. New York: Population Council.

Lutz, W, Sanderson, WC and Scherbov, S (eds) (2004) The End of World Population Growth in the 21st Century. London: Earthscan.

McDonald, P (2003) Australia's future population: population policy in a low-fertility society. In: Khoo S and McDonald P (eds) The Transformation of Australia's Population 1970-2030. Sydney: University of New South Wales Press: 266-279. 
McDonald, P and Kippen, R (1999) Population futures for Australia: the policy alternatives. Research Paper 5 1999-2000, Parliamentary Library, Parliament of Australia. Accessed 11 December 2000 from http://www.aph.gov.au/library/pubs/rp/1999-2000/2000rp05.htm

McDonald, P and Kippen, R (2002) "Projecting future migration levels: should rates or numbers be used?" People and Place 10: 82-83.

McDonald, P, Khoo, S and Kippen, R (2003) "Alternative net migration estimates for Australia: exploding the myth of a rapid increase in numbers." People and Place 11.3: 23-36.

National Research Council (2000) Beyond Six Billion: Forecasting the World's Population. Washington DC: National Academy Press.

Press, WH, Teukolsky, SA, Vetterling, WT and Flannery, BP (2001) Numerical Recipes in Fortran 77: The Art of Scientific Computing (Second edition). New York: Cambridge University Press.

Rees, P. (1989) Old model faces new challenges: a review of the state of the art in multistate population modelling. Working paper 531, School of Geography, University of Leeds, UK

Rogers, A (1990) "Requiem for the net migrant." Geographical Analysis 22: 283-300.

Rogers, A, Raquillet, R and Castro, LJ (1978) "Model migration schedules and their applications." Environment and Planning A 10: 475-502.

Smith, L (2003) The Australian Demographic Databank. Presentation to the Population Modelling and Forecasting workshop, The Australian National University, 13 February 2003. http://acpr.edu.au/Publications/Data\%20Bank\%20Presentation.pdf

Thatcher, AR, Kannisto, V and Vaupel, JW (1998) The Force of Mortality at Ages 80 to 120. Odense: Odense University Press.

Thatcher, R, Kannisto, V and Andreev, K (2002) "The survivor ratio method for estimating numbers at high ages." Demographic Research 6-1. http://www.demographic-research.org

United Nations (2003) World Population Prospects: the 2002 Revision. New York: United Nations.

Withers, G (2002) "Methods for projecting future migration levels: an assessment." People and Place 10.1: 84-86. 